\title{
A control engineering approach to the assessment of supply chain resilience
}

\author{
Virginia L. M. Spiegler ${ }^{\mathrm{a}, *}$, Mohamed M. Naim ${ }^{\mathrm{a}}$, Joakim Wikner ${ }^{\mathrm{b}}$ \\ ${ }^{a}$ Logistics Systems Dynamics Group, Cardiff Business School, Cardiff University, Aberconway Building, \\ Colum Drive, Cardiff, CF10 3EU, UK \\ ${ }^{b}$ Department of Management and Engineering, Linköping University, Linköping SE-58183, Sweden
}

\begin{abstract}
There is no consensus on the supply chain management definition of resilience. To aid in evaluating the dynamic behaviour of such systems we need to establish clearly elucidated performance criteria that encapsulate the attributes of resilience. A literature review establishes the latter as readiness, responsiveness and recovery. We also identify robustness as a necessary condition that would complement resilience. We find that the Integral of the Time Absolute Error (ITAE) is an appropriate control engineering measure of resilience when it is applied to inventory levels and shipment rates. We use the ITAE to evaluate an often used benchmark model of make-to-stock supply chains consisting of three decision parameters. We use both linear and non-linear forms of the model in our evaluation. Our findings suggest that optimum solutions for resilience do not yield a system that is robust to uncertainties in lead-time. Hence supply chains will experience drastic changes in their resilience performance when lead-time changes.
\end{abstract}

Keywords: Supply chain resilience, robustness, system dynamics

\section{Introduction}

The study of uncertainties and the development of risk management strategies have been promoted in various business domains, for instance managerial (March and Shapira, 1987; Bettis and Thomas, 1990; Yates and Stone, 1992), operational (Newman et al., 1993; Pagell and Krause, 1999), financial (Ashton, 1998), economical (Kahnemann and Tversky, 1979) and distribution (Lassar and Kerr, 1996).

In the context of purchasing and supply management, Zsidisin (2003) found that risk can be perceived as a multidimensional concept. Different companies will define risk based on their individual objectives and desired outputs. Moreover, within a company risk concepts

\footnotetext{
${ }^{*}$ Corresponding author

Email address: MarquesVL@cardiff.ac.uk (Virginia L. M. Spiegler )
} 
among different managers may be related to different outcome variables such as commercial (e.g. inventory levels), safety (e.g. risk to life) and political issues (e.g. political ramification) (Jüttner et al., 2003).

In this work we consider a supply chain perspective of risk. Hence when considering the supply chain's goal, potential risks involve any possibility of mismatch between supply and demand, as well as serving customers inefficiently. Therefore, any event that negatively affects the information and material flow between original supplier and end user should be considered as a risk of supply chain disruptions (Jüttner et al., 2003). Under these turbulent circumstances, the ability of a supply chain to be resilient becomes an important consideration (Pettit et al., 2010).

Despite the increasing number of research papers on supply chain resilience, there is still no consensus on its definition. Moreover, very few studies have attempted to measure this supply chain performance. In addition to this, despite the fact that system dynamics are identified as important sources of supply chain risk, the understanding of their impact on

supply chain resilience is minimal. In this work, we develop an assessment framework of resilience based on existing definitions and conceptual frameworks in the literature and on the dynamic behaviour of a supply chain. In doing so, we address the following research questions:

1. What are the existing resilience-related definitions in the supply chain literature?

2. What are existing ways to measure resilience and is there a suitable framework for doing so?

3. What is the role of system dynamics on resilience and how can a supply chain be designed in order to be resilient against such dynamics?

\section{Literature Review}

The term Supply Chain Management (SCM) was proposed by Oliver and Webber as recently as 1982 to designate a new form of strategic logistics management. Despite being relatively new, the discipline of SCM has been widely explored and the field of supply chain 
risk management has been pushed to the fore. However, the literature suggests that supply chain risk management has been only relatively recently considered as a major area of scholarly research and a more systematic and structured approach to this field can only lately be traced (Jüttner et al., 2003). Consequently, many concepts related to this research area such as flexibility, adaptability, resourcefulness, agility, resilience and robustness are often confused and unclear. Among the above terms we identified that resilience and robustness have been interchangeably used in supply chain literature. For this reason, we find it important to clarify the difference between the two definitions by conducting a literature review within the supply chain literature and within other sciences where these terms are more established.

The following sub-sections were written based on an exploratory literature review process, which was initiated by conducting keyword searches in multiple databases, such as ABI/INFORM Global, EBSCOHost, Scopus, ScienceDirect and Emerald. Google Scholar was also found to be useful to reach conference papers and technical reports. Among the keywords searched, we started with 'supply chain risk' in order to map out the research outlines of this field. In parallel, the keywords 'resilience' and 'robustness' were searched alone so as to identify the various fields using these concepts. Later, we narrowed our search by combining 'supply chain' with 'resilience', 'uncertainty', 'disruption' and 'robustness'. After this last search stage, we collated all the quantitative studies, 12 articles in total, and the qualitative studies which were relevant to developing our supply chain resilience assessment framework.

\subsection{Supply chain resilience}

The concept of resilience is multidisciplinary, arousing interest from both natural and social scientists. In physics and engineering, resilience is the ability of a material to return to its original form after being bent, compressed, or stretched. In other words, it is the ability of having an elastic behaviour (Pytel and Kiusalaas, 2003). In the supply chain literature, the idea of resilience has only recently emerged, and is essentially defined as "the ability of a system to return to its original state or move to a new, more desirable state after being disturbed" (Christopher and Peck, 2004). 
In particular, resilience has been used in examining responses to major supply chain disruptions and disaster relief efforts (Tomlin, 2006; Lodree Jr. and Taskin, 2007; Ratick et al., 2008; Falasca et al., 2008; Boin et al., 2010). This implies the strategic planning and positioning of supply chain parties. However, recent trends in the dynamics of market places and resulting complex supply chain procedures increase the importance of handling uncertainties which emerge at the operational level. Effectively managing operational risks directly improves finance performance (Pettit et al., 2010). Moreover, in global supply chains the longer transport distances and more resources involved increase chances for operational disruptions (Sheffi, 2005).

\section{Sources of risk}

According to Mason-Jones and Towill (1998), a supply chain will normally face uncertainties originating from customers or demand side, suppliers side, manufacturing processes and control systems - the Uncertainty Circle. Extending this framework, Christopher and Peck (2004) grouped supply chain risks into three categories: risks which are internal to the firm, risks which are external to the firm but internal to the supply chain and finally risks which are external to the supply chain.

The management of processes and operations is a fundamental task for guaranteeing continuous flows of goods and information within a single company and within a supply chain. At a higher level though, the mismanagement of assets and infrastructure can disrupt supply chain operations (Peck, 2005) and is therefore considered a potential cause of disruptions. Other sources of internal risk found in the literature are supply chain dynamics which are normally driven by different control system policies (Mason-Jones and Towill, 1998; Christopher and Peck, 2004; Colicchia et al., 2010a). By conducting multiple case studies on multinational companies, Colicchia et al. (2010a) found that supply chain dynamics appear in first place among a list of elements that cause supply chain disruption.

Regarding the risks which are external to the firm but internal to the supply chain, we have uncertainties arising from changes in supply and demand. Supply risk is well docu- 
mented by Zsidisin (2003) who listed and classified a set of sources and outcomes of supply risk. Between the late 1980s and early 1990s, many companies in the US decreased the numbers of their suppliers due to the costly and complex task of managing multiple suppliers. Consequently, supply costs and commitment risks were increased (Tang and Tomlin, 2008). Moreover, several works presented in a special issue on improving disaster supply chain management (read editors' comment in Boin et al. (2010)) highlight that companies with single sourcing are more prone to great losses in the event of natural disasters or terrorist attacks. Despite recent works focusing more on risks arising from supply side, disruptions also often occur due to changes in demand. Demand risk encompasses not only uncertainties in volume, but also in demand mix, i.e., in case of several product variants (Tang and Tomlin, 2008). Demand patterns might also change which would imply that the current forecast methods are no longer appropriate.

Finally, examples of external risks for a supply chain would include environmental factors, political and economical policies and social and technological changes.

\section{Resilience Strategies}

The literature is well-supplied with advice on how to build supply chain resilience, i.e., redundancy, flexibility, cultural change (Sheffi, 2005), situation awareness, vulnerability management (McManus et al., 2007), supply chain re-engineering, supply chain collaboration (Christopher and Peck, 2004), along with others. Tomlin (2006) presented some of these strategies categorised in mitigation and contingency tactics. The former implies taking actions before the disruption occurs in order to reduce this event's occurrence or to reduce its impact. Contingency strategies involve actions taken only after a disruptive event has happened. Tomlin (2006) also highlights that more than one strategy can be used to manage risks. However, since some of these actions are expensive some supply chains commit to a certain degree of financial risk - it is a trade-off. 


\section{Trade-off between resilience and cost}

Existing trade-off between supply chain resilience and costs is well acknowledged in the literature (Christopher and Peck, 2004; Sheffi, 2005; Sheffi and Rice, 2005). Indeed, it is costly to keep flexibility and redundancy through safety stocks, additional suppliers, extra backup sites and others. On the other hand, lack of resilience also accounts with other cost elements: poor customer service level, vulnerability and possible loss of control (Christopher and Peck, 2004), which are more difficult to be measured. Organizations will always have to make thoughtful choices based on their strategic objectives. Hence, it is important to consider this trade-off when undertaking research on supply chain resilience.

Despite the increasing number of publications on supply chain resilience, there are few studies which attempt to create a quantitative framework for assessing supply chain resilience performance (Datta et al., 2007; Falasca et al., 2008; Ratick et al., 2008; Colicchia et al., 2010b; Carvalho, 2011). Most existing studies have provided more qualitative insights to the problem and focus more on identifying sources of risks and on determining mitigation and contingency strategies. Quantitative researchers have focused on reducing the likelihood of the occurrence of disruptive events and/or developing means of overcoming disruptions if such events occur (Tomlin, 2006; Lodree Jr. and Taskin, 2007; Wilson, 2007; Tang and Tomlin, 2008; Mitra et al., 2009; Skipper and Hanna, 2009; Wagner and Neshat, 2010). They do not explicitly state that supply chain resilience is achieved or measured at any point in their work. Despite that, the literature refers to some of those authors as contributors to supply chain resilience research and for this reason we will review each of them. A summary of these works can be found in Table 1 in which the five first rows refer to supply chain resilience-focused research and the remaining concerns supply chain risk-focused research.

To our knowledge, the first attempt to analytically assess supply chain resilience was made by Datta et al. (2007). The authors evaluated the impact of different strategies when considering the dynamics of demand, production and distribution functions. They considered the Customer Service Level (CSL), average inventory level and production change-over time 
to assess the operational resilience. In summary, they found that flexibility of production and distribution procedure is a key factor in coping with demand changes. However, their model does not consider any other factors (such as cost) that would enable trade-off analysis. Falasca et al. (2008) developed a simulation-based framework for helping managers to (re-) design supply chains in order to be resilient against environmental uncertainties. Despite being only a theoretical framework, the authors addressed the necessity of minimising the immediate impact caused by disruption and the time to recover, and therefore minimising the "resilient triangle" (Tierney and Bruneau, 2007), a concept that will be covered in the next section. When designing supply chains, Falasca et al. (2008) argue that nodes criticality, complexity and density should be taken into account. Also looking at environmental factors and supply chain design, Ratick et al. (2008) developed a model which helps to allocate a cost-effective number of facilities in areas of different geographical risk factors. Focusing on supply uncertainties, Colicchia et al. (2010b) uses the length and variation of the supply leadtime as indicators of supply chain resilience. They argued that a better understanding of the risk sources for specific supply chain settings can enable the design of a more resilient supply chain. Also based on the concept of the "resilient triangle" (Tierney and Bruneau, 2007) and using exploratory case studies and empirical data, Carvalho (2011) developed a model to create a composite performance measure: the resilience index. By applying structured interviews and calculating the resilience index, the authors could compare different companies resilience performance. However, many of the metrics used depend on qualitative perception and personal judgement from managers and are subjected to possible bias. Moreover, this measure is suitable for analysing current state business processes but is not applicable to investigating 'what if' scenarios. 


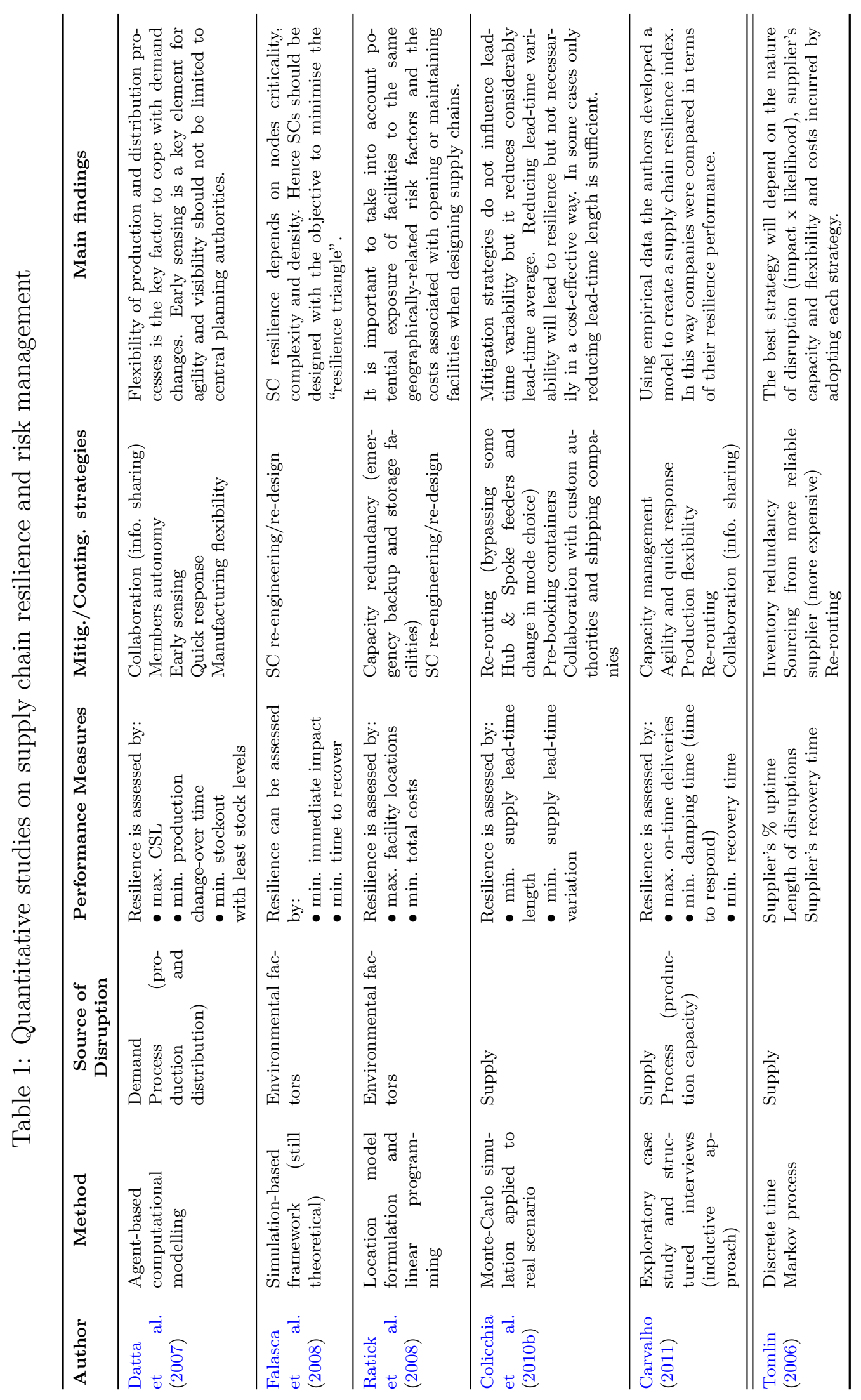




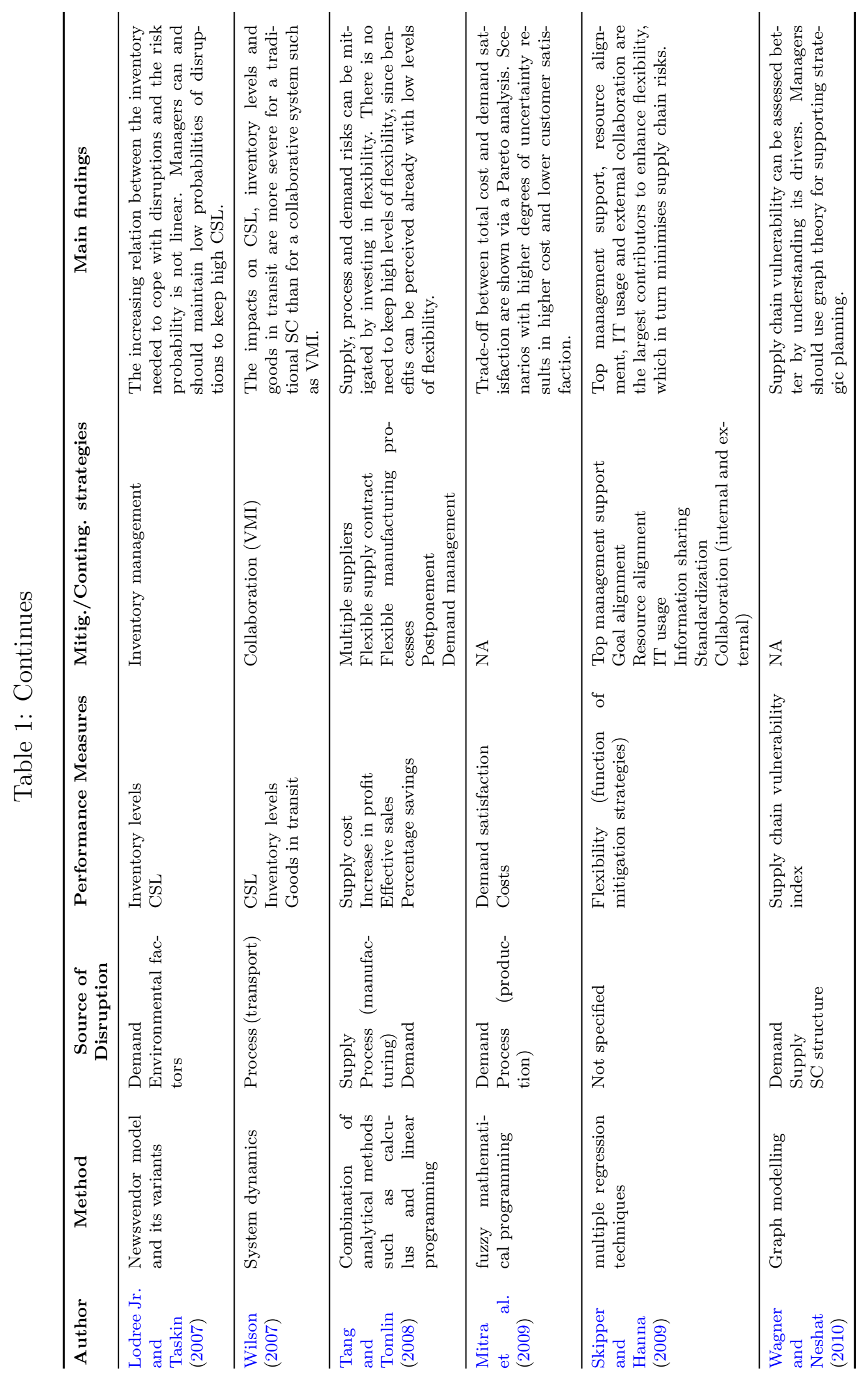


Lodree Jr. and Taskin (2007) evaluated the impact of demand uncertainty and occurrence of an extreme event (such as a disaster) on inventory levels and customer service levels (CSL) by finding stock-outs probabilities. They compared the inventory levels in the classic newsvendor solution with levels needed in case of uncertain situations. While Lodree Jr. and Taskin assessed the effects for the customer side, Tomlin (2006) determined economical choices of mitigation and contingency strategies in order to overcome unreliable supply. His model considered the supplier's percentage uptime and the length of disruption which indicate the level of risk that supply chains are exposed to.

The only work that applied the system dynamics research method was undertaken by Wilson (2007). The author analyses how a more collaborative supply chain, such as the vendor-managed inventory (VMI) can help to overcome the impact caused by disruptions in transport processes on customer service levels, inventory levels and goods in transit.

Tang and Tomlin (2008) and Skipper and Hanna (2009) demonstrated the importance of flexibility on mitigating supply, demand and process risks. Complementarily, while the latter shows through regression techniques that top management support, resource alignment, IT usage and external collaboration enhance flexibility, the former evidenced how flexible activities, such as manufacturing processes, postponement, adjustable supplier contract and demand management through flexible pricing can improve supply chain performances. Finally, both Mitra et al. (2009) and Wagner and Neshat (2010) developed techniques that support trade-offs visualisation and the understanding of many risk drivers.

Figure 1 summarises what has been found in the literature regarding sources of risk and strategies to anticipate, mitigate and overcome disruptions. Moreover, the figure also lists the criteria that were used to evaluate supply chain resilience and/or disruptions' likelihood and characteristics (these measures are listed followed by an asterisk). However, some of these works designed models which are more appropriate to evaluate resilience of individual companies and not the supply chain as a whole. For instance, in Figure 1 we argue that resilience should be measured at the interface between the supply chain and the end customer regardless where in the supply chain the disruption occurred. We agree that minimising risk 


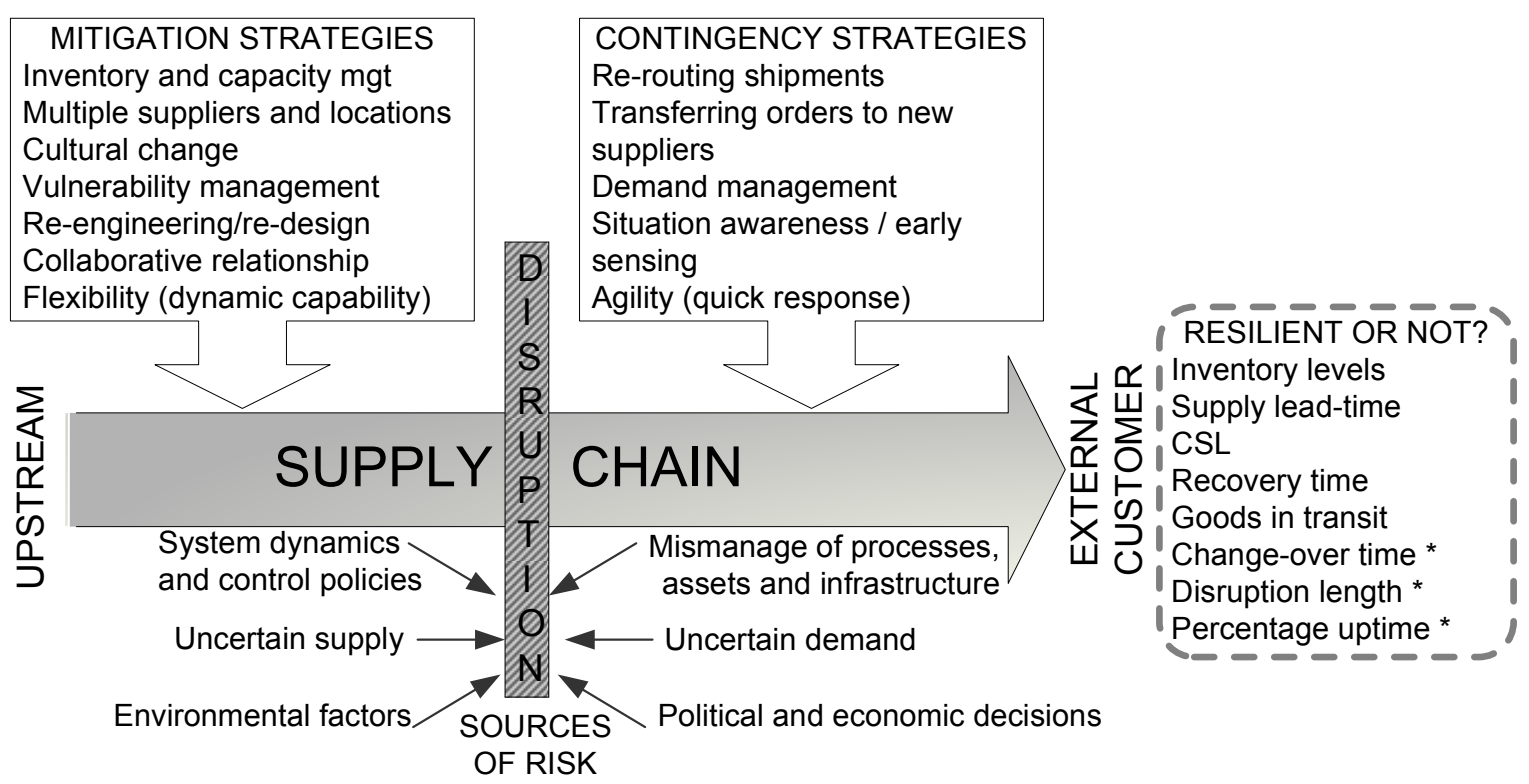

Figure 1: Supply chain strategies for improving resilience against disruption

may lead to supply chain resilience but resilience should not be assessed only by evaluating disruption aspects. For example, the impact of a long or short disruption in the supply of raw material on customer service may be the same depending on the inventory policy chosen by the downstream companies. Of course that the cost of keeping inventory sufficient to cover a long disruption is higher, but being resilient is reported to be expensive and managers have to find a balance between cost and resilience. In other words, we defend a systems view of supply chain resilience since that, in many cases, the effort of mitigating a type of disruption might initiate another disruption elsewhere. For instance, re-routing shipments may affect the transport available capacity. 
Table 2: Scope of this work and contribution to the literature
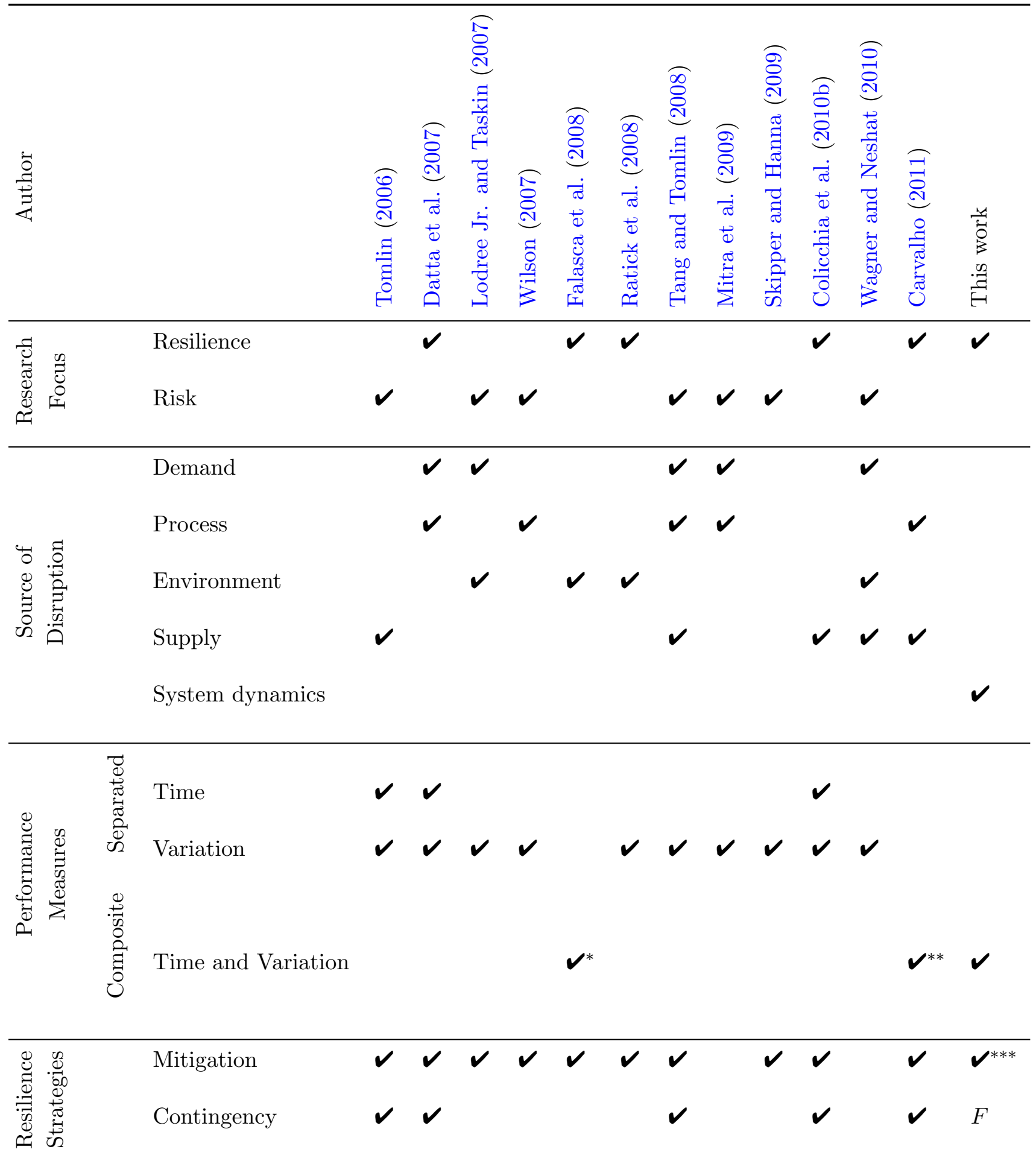

* The authors presented the simulation-based framework but did not conduct experiments ** Only applicable to case studies, specially in automotive supply chains

*** We consider the system re-design by finding optilnum parameter setting for resilience $F$ - Future research 
In this work, we take a systems dynamics approach to create an analytical framework for assessing supply chain resilience. Moreover, this work focusses on analysing the impact of systems dynamics and different control policies on resilience performance. This complements the literature since no work has been found to analyse this source of risk despite being highlighted by Mason-Jones and Towill (1998) as a central activity. It is through control systems that demand, supply and processes are estimated. In addition to this, we advocate the use of a composite performance measure in which both dimensions, time and variation, are taken simultaneously into account. The literature postulates that resilience implies not only minimising deviations from a targeted state, but also re-achieving this target as fast as possible. Table 2 highlights the scope of this research and its contribution to the literature. First, we developed a framework for assessing supply chain resilience in both make-to-stock (MTS) and make-to-order (MTO) systems. Then we tested the developed measure using a MTS supply chain model. Finally, we suggested a re-design of the supply chain to improve the resilience performance. For future research we intend to include more solution strategies, such as contingency strategies, in our model.

\subsection{Robust control systems}

Before we continue to the next section, it is important to introduce the concept of robustness. The term robustness has been used in supply chain research interchangeably with resilience. For instance, Asbjørnslett (2008) states that a "supply chain is robust, or resilient, with respect to a threat, if the threat is not able to produce any 'lethal' effects on the system". This means that both robustness and resilience involve post-disturbance recovery. According to Asbjørnslett, what differentiates a robust system from a resilient system is that the former has the ability to resist a disturbance and retain the same previous state. The latter has the ability to adapt and achieve a new stable situation. The latter definition is more in line with the resilience definition by Christopher and Peck (2004) previously given.

According to Christopher and Rutherford (2004), robustness differs from resilience by having 'Lean Thinking' as the central strategy while risk management is a key strategy to achieve a resilient supply chain. Moreover, they argue that, since a robust system is able to 
respond to reasonable variations and a resilient system responds to major changes in input, a resilient supply chain will be robust while the reverse is not always true.

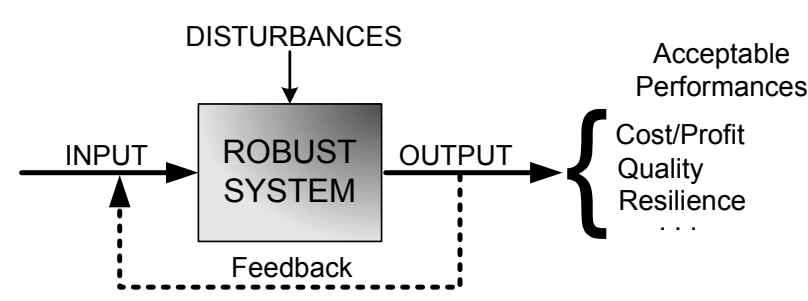

(a) A robust system under disturbances

\begin{tabular}{|l|c|c|}
\cline { 2 - 3 } \multicolumn{1}{l|}{ Changes in : } & Resilience & Robustness \\
\hline System structure & & \\
\hline Parameters & & \\
\hline Input types & & \\
\hline
\end{tabular}

(b) Changes accounted by resilient and robust systems

Figure 2: Difference between resilience (system performance) and robustness (system characteristic)

In order to avoid confusion, here we use a control engineering definition of robustness. A system is robust when the system has acceptable changes in performance due to model or parameter changes and moderate modelling errors (Dorf and Bishop, 1998). Hence, each system has to define which performances should be retained in case of disturbances. In this work, the performances in question are the supply chain resilience and the system responses. So, a robust supply chain should be designed to function properly even in the presence of uncertain parameters (for instance, the lead-time). Hence we only consider the changes in system parameters when accounting for robustness. In contrast to other supply chain authors, we find that changes in input are not relevant in determining whether a supply chain is robust. Figure 2 illustrates the difference between resilience and robustness. In Figure 2(a), robustness represents the characteristic of the system which should be designed to retain performance even in case of disturbances, model inaccuracies and changes. Resilience is the performance of the output which should return to its original state after being disturbed. Since this work will be looking at uncertainties caused by control systems and supply chain dynamics, in other words changes in the systems parameters, resilience and robustness will be assessed and compared. 


\section{Assessing supply chain resilience}

When reviewing the supply chain literature on resilience, we found a number of contradictions and a domination of qualitative aspects that are difficult to measure. In addition to this, several metrics have been used by quantitative researchers to assess resilience. It is important to develop a single measure of resilience to ensure consistency and repeatability in results. In order to achieve that, a clearer and exact concept is needed.

By using theory building, Ponomarov and Holcomb (2009) developed a holistic conceptual

framework for supply chain resilience which was defined as: "the adaptive capability of the supply chain to prepare for unexpected events, respond to disruptions, and recover from them by maintaining continuity of operations at desired levels of connectedness and control over structure and function". This definition implies achieving:

1. Readiness: being prepared or available for service. The implication of this definition is whether the supply chain can continue providing goods / services at reasonable costs according to the end customers requirements. Hence, maintaining a Minimum Reasonable Inventory (MRI) (Grünwald and Fortuin, 1992) or a Minimum Reasonable Order Book (MROB) (Wikner et al., 2007) may be appropriate courses of action.

2. Response: reaction to a specific stimulus. A quick response implies minimising the time to react to disruptions and beginning the recovery stage.

3. Recovery: a return to 'normal' stable or steady state conditions.

Sheffi and Rice (2005) outlined a graph that illustrates how disruptions would affect companies performance which can be measured by sales, production levels, profits and customer service. Additionally, their illustration demonstrates different phases of the system's performance response: after a disruption the performance decreases but as actions are taken the system's performance will be gradually restored. Similarly, Asbjørnslett (2008) and Tierney and Bruneau (2007) also highlight the relation between a disruptive event and business indicators. Tierney and Bruneau (2007) call this loss of functionality from disruption followed by a gradual recovery the 'resilient triangle'. According to them, this triangle should be minimised. 


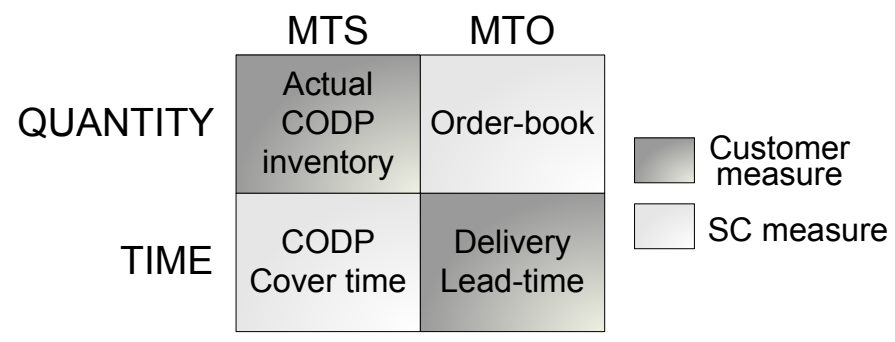

Figure 3: Different dimensions for assessing supply chain resilience performance

When deciding which supply chain performance should be analysed we consider the supply chain's objective which is satisfying customers. The way a supply chain targets customer satisfaction will depend on the nature of its business. For instance, in a MTS system products are produced based on a demand forecast while maintaining MRI. On the other hand, MTO products, normally with high holding costs, are manufactured only after an order is confirmed. Hence, MTO supply chains are concerned with delivering the orders in a minimum reasonable time (Wikner et al., 2007). In addition to this, it is important to mention that MTS may also refer to a part of the system situated in the upstream from the customer order decoupling point (CODP), whereas MTO would be in the downstream from CODP. Hence both can be parts of one production system. Figure 3 illustrates two different dimensions, quantity and time, that can be used to measure supply chain resilience of MTS and MTO systems. Moreover, the figure highlights which measures concern the customers and which performances interest the supply chain. For instance, while for MTS supply chains the inventory cover time is more relevant from a control perspective, the customer is more interested in the amount of inventory still available. In MTO systems, supply chains are concerned with the aggregate number of order-based backorders awaiting production and delivery - the order book (Wikner et al., 2007), whereas the customer's perceived measure is the lead-time between the placement of his order and receiving the product. In this context, time and quantity can be said to be two different sides of the same coin since they are connected by the following relation with demand: time = quantity/demand. 
Building on Sheffi and Rice (2005), Asbjørnslett (2008), Tierney and Bruneau (2007) and using the supply chain resilience definition by Ponomarov and Holcomb (2009), we present Figure 4, where a key indicator of supply chain resilience is the impact any disturbance has on the end customer, no matter where in the supply chain that disruption occurs. Therefore resilience may be measured at the interface between the supply chain and the end customer.

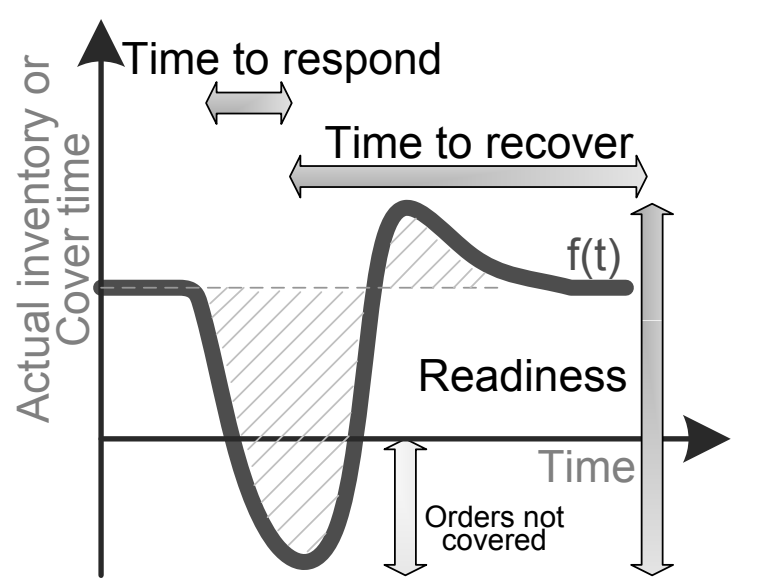

(a) MTS

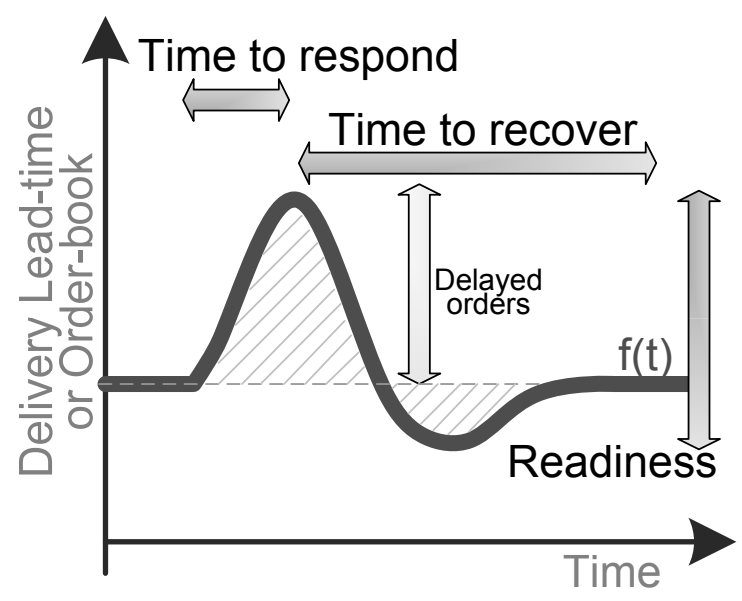

(b) MTO

Figure 4: Assessing supply chain resilience: readiness, response and recovery

Based on the foregoing literature synthesis, Figure 4 represents our proposed systems dynamics metrics for assessing supply chain resilience. The actual inventory or cover time in the MTS and the delivery lead-time or the order-book in the MTO system should be monitored and evaluated as surrogates of the customer service level. After a disturbance, both systems show signs of decline in service level until a point when they start to improve again. This corresponds to the response time. Then, the recovery process starts and lasts until the service level again achieves the desired target. The readiness is represented by the maximum peak to trough vertical displacement. The smaller the vertical displacement is, the more prepared or available for service, in other words, the more ready the supply chain may be said to be. Taking all the attributes of the system curve into account, we propose 
that the smaller the area between the actual response and the target level, as highlighted in the figure, and the faster the response and recovery are, the more resilient the supply chain can be said to be. This follows the same reasoning as minimising the 'resilient triangle', however in our approach we consider that the output may overshoot and/or undershoot before recovering, hence not assuming a triangular shape but an oscillatory behaviour.

In control engineering, the integral of time multiplied by the absolute error (ITAE) is used to emphasise long duration errors and is recommended for the analysis of systems which require fast settling time (Dorf and Bishop, 1998). The minimum value of ITAE corresponds to the best response and recovery with the lowest deviation from the target, or readiness. The ITAE is given by:

$$
I T A E=\int_{0}^{\infty} t .|e(t)| \mathrm{d} t=\lim _{\delta t \rightarrow 0} \sum_{t=0}^{\infty} t|e(t)| \delta t
$$

where $e(t)$ is the error in customer service related measure. Note that if the system does not reach the steady state or has a steady state error, ITAE will tend to infinity implying a significant lack of resilience. By using this performance index, two dimensions of time, which we relate to response and recovery times, and one dimension of variation (readiness) are taken into account. Hence, more weight is given to time.

\section{The system dynamics model}

We chose the Automatic Pipeline Inventory and Order Based Production Control System (APIOBPCS) (John et al., 1994) because this decision support system considers inventories both on hand and in process. Wikner et al. (2007) have also shown its analogue with MTO systems in the form of an Order Book Based Production Control System.

The linear and non-linear representations of APIOBPCS are illustrated in Figure 5. The value of the current demand is exponentially smoothed which can be represented by a first

order lag. Hence, the parameter $T_{a}$ represents the time to average demand such that the exponential smoothing function $\alpha=1 /\left(1+T_{a} / \Delta t\right)$ (John et al., 1994).

The inventory and pipeline policies are characterized by feedback loops. The inventory 


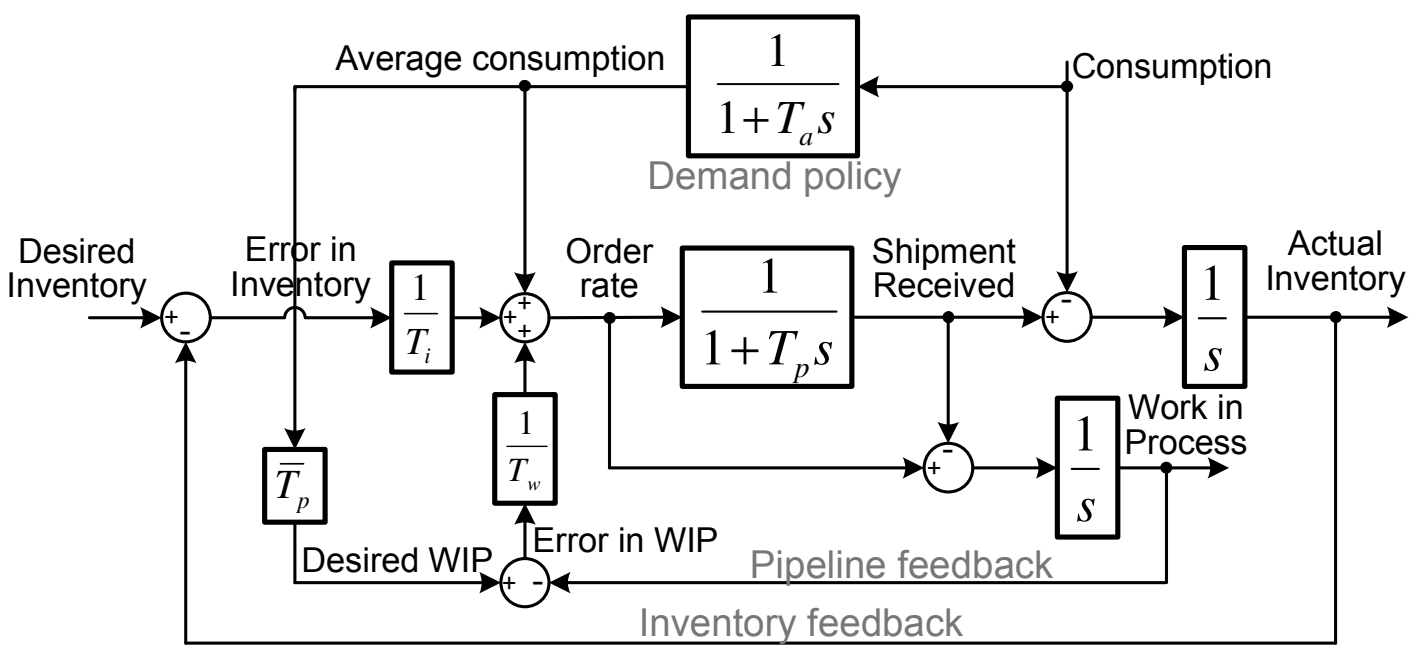

(a) Linear Model

Source: John et al., 1994

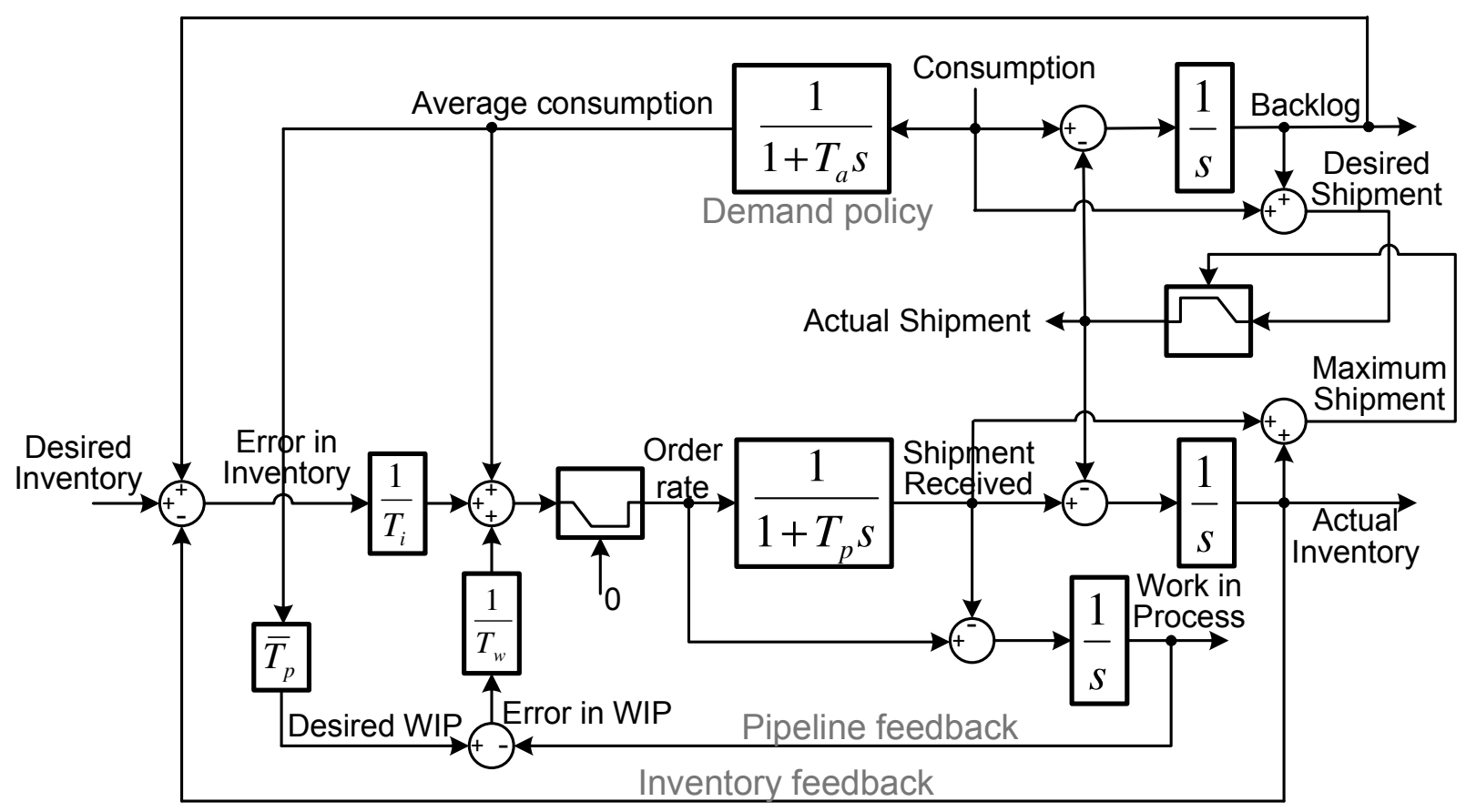

(b) Non-Linear Model

Figure 5: Block diagram representations of APIOBPCS 
control is concerned with the rate $\left(1 / T_{i}\right)$ at which a deficit in inventory is recovered. This policy is responsible for reducing the discrepancy between desired and actual inventory. The pipeline policy considers the actual work in process $(W I P)$ and the time $\left(T_{w}\right)$ it takes to recover to target levels. While the desired inventory is a constant value, the desired WIP is function of the expected lead-time $\left(\bar{T}_{p}\right)$ and the forecasted demand.

Finally the orders placed onto the supplier or production will take into account the forecasted demand and the errors in inventory and WIP. The receipt of material is represented by a first order lag with a lead-time $T_{p}$.

The focus of this paper will be to show how different supply chain designs, achieved through changes in the control parameters, $T_{a}, T_{i}$ and $T_{w}$, and the lead-time $T_{p}$ will affect supply chain resilience and robustness. Moreover, we will determine which supply chain design provides better supply chain resilience performance. We will also investigate if there is a trade-off between resilience and operational costs. Since at this stage we only consider the system re-design as a mitigation strategy, the costs arising from keeping redundancy and flexibility do not pertain to our model. The only cost we consider is the increase of production overheads due to system dynamics: the production on-costs, which are functions of the chosen set of parameters and the lead-time. The production on-costs are estimated to be "proportional to the cubic function of the area between the oscillation output [order rate] and the neutral axis" (Stalk and Hout, 1990; Towill et al., 1992).

\subsection{Linear model}

From the linear block diagram in Figure 5(a), it is possible to determine the actual inventory $(A I N V)$ transfer function in relation to the input consumption $(C O N S)$ :

$$
\frac{A I N V}{C O N S}=\frac{\left[\left(T_{i} \bar{T}_{p}-T_{i} T_{p}\right)-\left(T_{i} T_{w} T_{p}+T_{a} T_{i} T_{p}+T_{a} T_{i} T_{w}\right) s-\left(T_{a} T_{i} T_{w} T_{p}\right) s^{2}\right] \cdot \frac{1}{T_{a} T_{i} T_{w} T_{p}}}{\left(s+\frac{1}{T_{a}}\right)\left[s^{2}+\left(\frac{1}{T_{p}}+\frac{1}{T_{w}}\right) s+\frac{1}{T_{i} T_{p}}\right]}
$$

One of the poles is easily identified $\left(-1 / T_{a}\right)$ and the other two poles $\left(p_{1}\right.$ and $\left.p_{2}\right)$ are equal 
to the roots of the quadratic equation in the denominator.

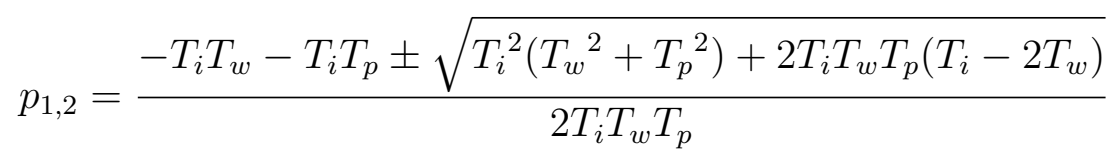

We use the step response to evaluate the impact of systems dynamics. By using the method of partial fraction expansion, the time function for the actual inventory can be finally determined as:

$$
\operatorname{ainv}(t)=A \cdot e^{-\frac{t}{T_{a}}}+B \cdot e^{p_{1} t}+C \cdot e^{p_{2} t}
$$

where $\mathrm{A}, \mathrm{B}$ and $\mathrm{C}$ are coefficients related to the system poles and D is the coefficient of the step input pole $(s=0)$. Assuming that the expected lead-time is equal to the actual lead-time $\left(\bar{T}_{p}=T_{p}\right)$, the coefficient values are:

$$
\begin{aligned}
A & =\frac{-T_{i} T_{a}^{3}\left(T_{w}+T_{p}\right)}{\left(T_{a} p_{1}+1\right)\left(T_{a} p_{2}+1\right)} \cdot \frac{1}{T_{a} T_{i} T_{w} T_{p}} \\
B & =\frac{-T_{i}\left(T_{a} T_{w}+T_{a} T_{p}+T_{w} T_{p}+p_{1} T_{a} T_{w} T_{p}\right)}{\left(p_{1}-p_{2}\right)\left(p_{1}+1 / T_{a}\right)} \cdot \frac{1}{T_{a} T_{i} T_{w} T_{p}} \\
C & =\frac{-T_{i}\left(T_{a} T_{w}+T_{a} T_{p}+T_{w} T_{p}+p_{2} T_{a} T_{w} T_{p}\right)}{\left(p_{2}-p_{1}\right)\left(p_{2}+1 / T_{a}\right)} \cdot \frac{1}{T_{a} T_{i} T_{w} T_{p}} \\
D & =\frac{T_{a}}{p_{1} p_{2}}\left(T_{i} \bar{T}_{p}-T_{i} T_{p}\right) \cdot \frac{1}{T_{a} T_{i} T_{w} T_{p}}=0
\end{aligned}
$$

The second term, which is a division by $T_{a} T_{i} T_{w} T_{p}$, was left separate because it indicates that the results were normalized according to the leading coefficient of the denominator.

Note that the equation above is appropriate only when the values of the poles are real and distinct. In case of repeated poles the special case of the partial fraction expansion method has to be used. For instance, the three poles will be equal when $T_{a}=T_{i}=T_{w}=T_{p}$ and $p_{1}$ is equal to $p_{2}$ when $T_{i}=T_{w}=T_{p}$. For each case, a new time equation can be found (refer to Appendix A).

Finally, we can find the ITAE expression for the actual inventory time equation. We consider the target inventory as being equal to zero. Hence, the error in the inventory 
$(E I N V)$ is the difference between zero and the actual inventory. However, since the ITAE involves the integral of an absolute function, there are some aspects of the actual inventory function to be considered. After the step change, if the inventory amount drops and recovers without overshooting again, then the ITAE can be calculated as:

$$
I T A E_{\text {einv }}=-\left(A \cdot T_{a}^{2}+\frac{B}{{p_{1}}^{2}}+\frac{C}{{p_{2}}^{2}}\right), \text { only for } T_{a}>0 \text { and } p_{1}, p_{2}<0
$$

Note that when $T_{a}$ is negative or $p_{1}$ and $p_{2}$ are positive, the system is not stable since the poles would be in the right half of the s-plane. In other words, the inventory response would never reach steady state implying lack of resilience $(I T A E=\infty)$. For more detail on stability and performance of the IOBPCS (Inventory and Order Based Production Control System) family the reader can refer to Disney and Towill (2002); Disney et al. (2006); Disney and Grubbström (2004) and ?.

In the case of overshoot, there is a need to determine the zeros of the function einv $(t)$ and calculate the integral by parts, considering the absolute value of each part. Alternatively, we use Equation (1) with $\delta t=0.05$ and we run a simulation for $t=1000$. Cross-checking the mathematical formulation with simulation results, a good approximation for ITAE can be found without concerning about positive and negative areas arising from overshoots.

We used MATLAB ${ }^{T M}$ for the simulation of one-echelon supply chain using both continuous and discrete time approaches. It was noted that, for the continuous model, the minimum ITAE occurs when $T_{i}=0$ and is equal to zero. The reader can check this result by substituting $T_{i}=0$ in Equations 5 and 6 but considering that the second term of Equations 5 (the leading coefficient) would now be $T_{a} T_{w} T_{p}$. This results implies that this single-echelon supply chain would review inventory continuously and that the supplier would replenish material continuously as well. However, most supply chains review their inventory and receive material periodically. Hence, we opted for the discrete simulation with a pure delay of the completion rate/shipments received where $\Delta t=1$. In addition to this, the discrete simulation will provide an equitably comparison with the non-linear case. 


\subsection{Non-linear model}

The limitation of the linear control model when evaluating supply chain resilience is that regardless of the actual inventory level the customer will always receive the goods. From Figure 5(a), it can be observed that the customer consumption is subtracted from the inventory even if no products are available. In addition to this, order rates can be negative when the error in inventory and/or WIP are negative. This can occur when the actual inventory or WIP is greater than desired. This negative order rate implies that goods can be returned back to the supplier. Both characteristics outlined are unrealistic traits of the linear model.

For these reasons, we use a non-linear model, Figure 5(b), to forbid the returning of goods back to the supplier and to investigate how the backlog situation will affect the shipments to customers. We represent these non-linearities as in Wikner et al. (1992) where the authors managed to translate the clip function used by Forrester (1961)'s DYNAMO program into a block diagram representation. In our case, the clip function in the order rate means that the minimum possible value of the order rate is zero while in the actual shipment the clip function denotes that the maximum possible value for the shipments sent is the sum of the actual inventory and shipment received. When the shipments sent are not equal to the customer demand, then backlog builds up. Hence, the desired shipment is the customer demand plus any backlog. Note that, as represented in Figure 5(b), backlog and inventory will not occur simultaneously and will not be negative because of the clip function. Hence, the error in inventory will then be the desired inventory level minus the holding inventory plus the backlog, since backlog represents a negative inventory level.

It is not possible to derive a single transfer function representation of the actual inventory for the non-linear model and consequently we cannot exactly determine the step response function to calculate the ITAE values as we did in section 4.1. Hence, as we did for the linear model, a difference equation simulation approach is used to evaluate resilience in this model. As shown in the linear model, the simulation provided very good approximation to the mathematical formulation, hence it should not be a concern here. The reader can 


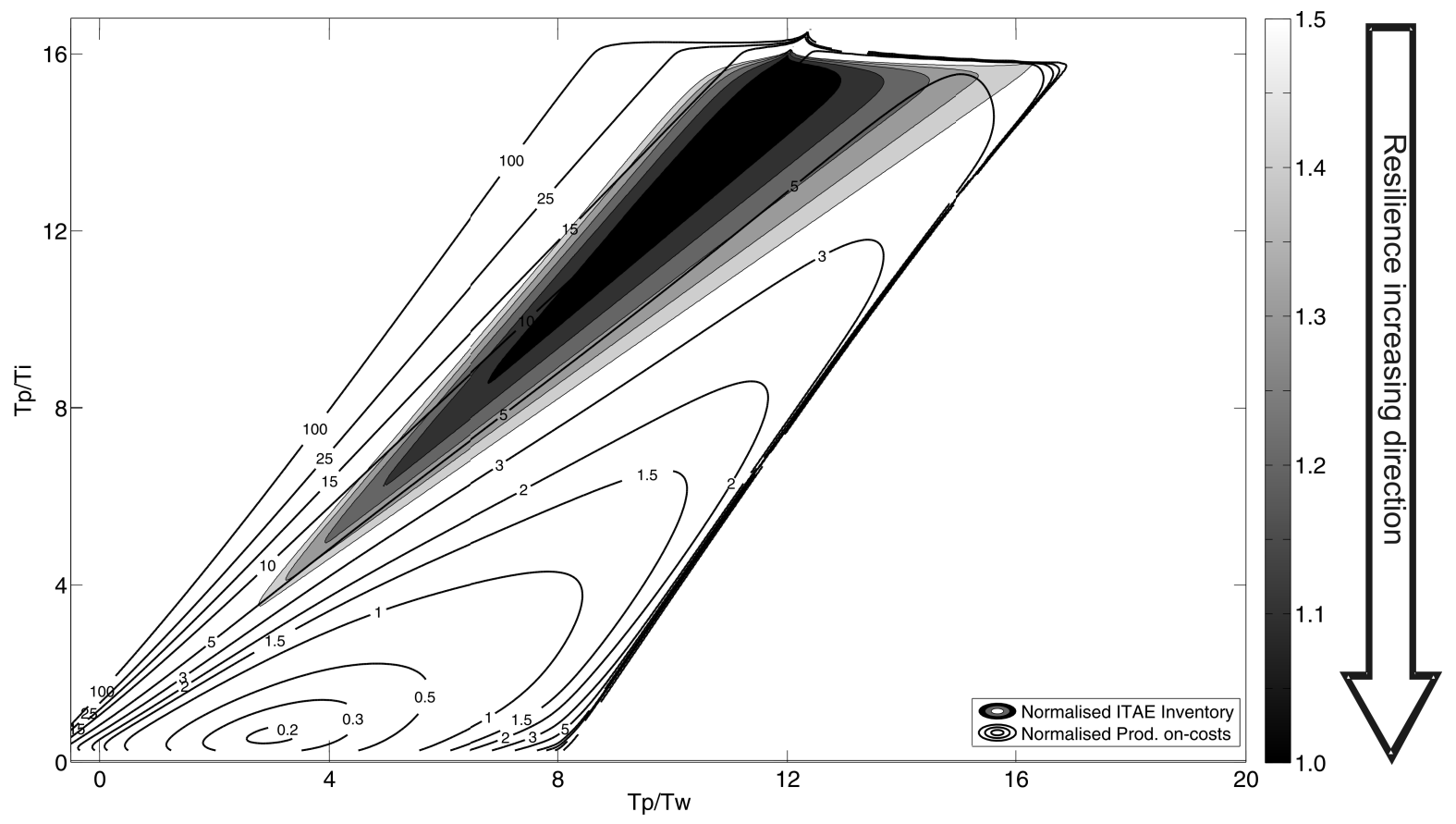

Figure 6: Trade-off between resilience and cost $\left(T_{p}=8\right)$

consult Appendix B for the difference equations used for the discrete simulation of the nonlinear APIOBPCS model. These equations were firstly deducted by Shukla et al. (2009) who studied the 'backlash' phenomenon on shipments and further applied by Marques et al. (2010) who studied capacitated logistics operations. In order to verify our difference equation simulation of the non-linear model we used Simulink with a fixed-step solver and Euler's method of integration to replicate the block diagram representation of Figure 5(b).

\section{The impact of supply chain dynamics on supply chain resilience}

\subsection{Analysis of the linear case: no-backlog situation}

Our findings start by investigating whether our proposed method to assess resilience is consistent with the descriptions in the literature.

Since $T_{a}$ is a control parameter in the feedforward path and therefore not interfering in the closed-loop stability conditions (see Equation 3), we kept it positive (to keep system 
stable) and initially fixed to 6 weeks. The influence of this consumption averaging constant on supply chain resilience will be discussed later. Hence, by varying the control parameters $T_{i}$ and $T_{w}$ as a function of $T_{p}$, the resilience area and the production on-costs for a oneechelon supply chain could be illustrated (Figure 6). The darker area of the greyscale image represents the parameter settings which result in smaller ITAE values for inventory.

We set the scenario where lead-time is equal to 8 weeks as the nominal setting. The minimum ITAE performance index found for this scenario is when $T_{p} / T_{w}$ is 11.67 and $T_{p} / T_{i}$ is 14.78. This is the point of maximum resilience that the system can achieve. In order to normalise the results, all the ITAE performance indices were divided by the minimum index value. In this way, we can discuss the change in resilience performance in percentage relation to the maximum resilience point of the nominal scenario. For instance, the area where the normalised ITAE values are equal to 1.2 in Figure 6 means that the resilience performance dropped by $20 \%$ when changing to this set of parameters. The contour black lines correspond to the increase in production overheads due to the system dynamics. Our calculations assume that if the actual order rate response is equal to demand, the production costs would not be affected. Note that the white areas and where there are no on-costs contour lines, that is, where ITAE and on-costs approach infinity, represent unstable regions of the discrete linear model.

Figure 6 also indicates a trade-off between supply chain resilience and production oncosts. The set of parameters which improve response and recovery time and minimise the deviation from the target inventory would imply increased variation in the production schedule. This is consistent with the literature in which authors described that increased resilience through flexibility and agility would lead to increased operational costs (Christopher and Peck, 2004; Sheffi, 2005; Sheffi and Rice, 2005). While the model and associated simulation do not explicitly measure other related costs such as poor customer service level, vulnerability and possible loss of control due to non-resilience (Christopher and Peck, 2004), they are implicit in our ITAE measure of resilience. 


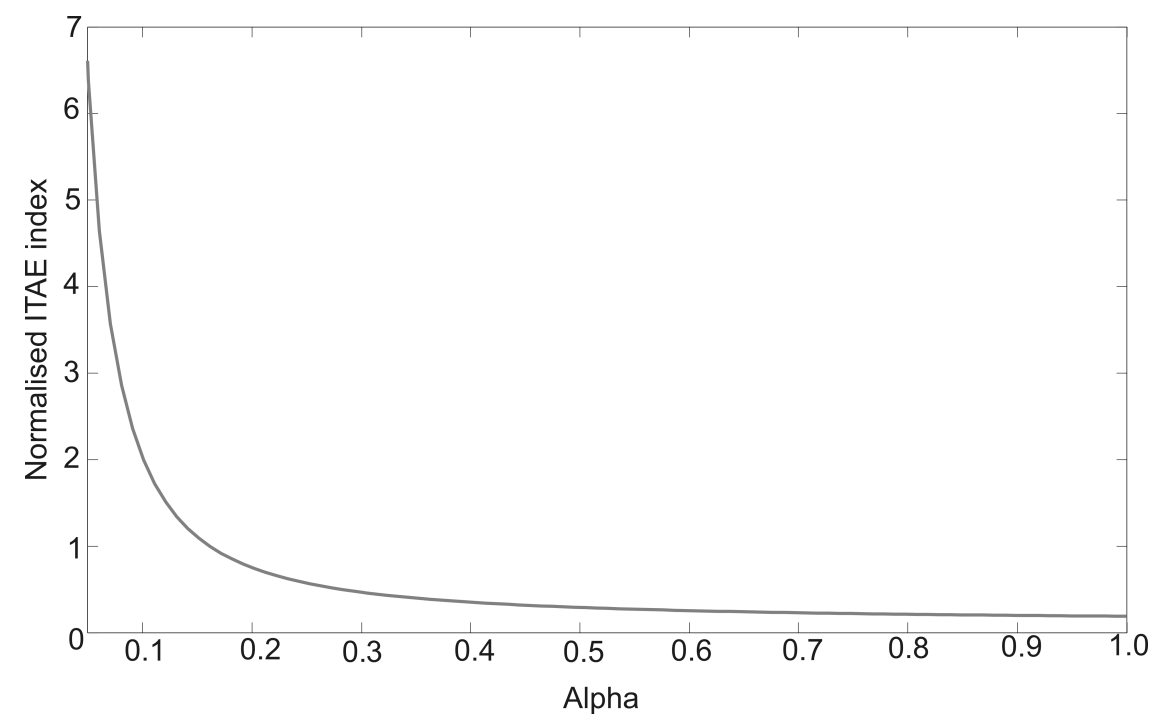

Figure 7: The effect of the forecast policy

The effect of $\boldsymbol{T}_{\boldsymbol{a}}$ Despite the parameter $T_{a}$ not interfering with the closed-loop stability conditions, we checked its impact on resilience performance. When considering $T_{i}=T_{w}$ and $\alpha$ values varying between 0 and 1 , we found that minimum ITAE values are achieved when $T_{a}=0$ or $\alpha=1$ (see Figure 7). This means that resilience can be improved when forecasts are not taken into account. Order rate is then based on the incoming demand and inventory errors only, i.e. the supply chain substitutes a production levelling strategy with a chase. This finding is consistent with Christopher and Peck's (2004) observation that "forecast-driven" organizations are more prone to vulnerabilities than "demand-driven" organizations. It should be noted, however, that this approach yields a considerable peak in order requirements increasing production-costs.

From Figure 7, we can also observe that as $\alpha$ reaches zero, the ITAE approaches infinity since the system will be in the marginally stable region. With this parameter choice, the order rate will be only based on forecasts and will be not consider changes in demand, which implies lack of resilience. 


\section{Sensitivity Analysis}

Any supply chain design, namely the selection of control parameters, is based on the assumption of a known and given lead-time. By undertaking a sensitivity analysis, it is possible to check on the robustness of any given supply chain design due to possible changes in lead-time. The lead-time is an important physical parameter that a supply chain designer cannot select or control.

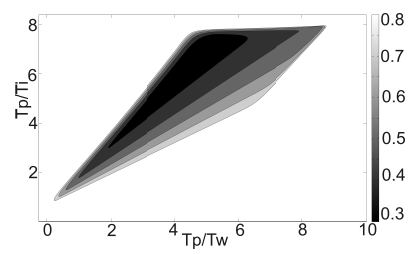

(a) $T_{p}=4$

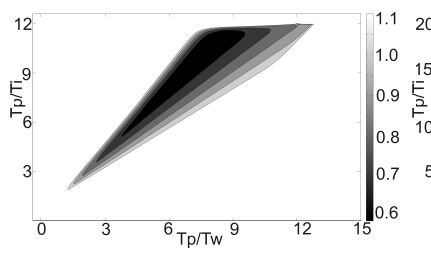

(b) $T_{p}=6$

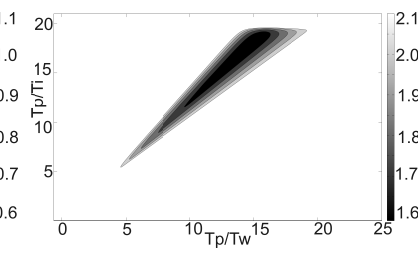

(c) $T_{p}=10$

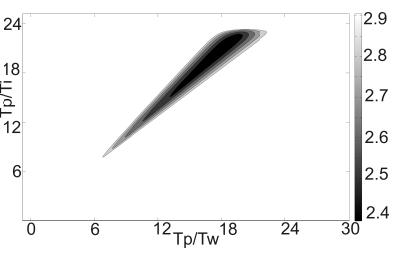

(d) $T_{p}=12$

Figure 8: Assessing robustness on inventory responses due to changes in lead-time

Given the nominal scenario, we evaluate the impact of $\pm 25 \%$ and $\pm 50 \%$ changes in leadtime on resilience of the system. As the lead-time increases, not only does the resilience area become smaller but also the minimum ITAE values increases (See Figure 8). This means that managers must be careful with their choices of parameters because a change in lead-time can move their inventory response and recovery out of the resilience area.

Table 3 contains the results of the robustness test of the inventory responses. After determining the parameter setting that minimised the ITAE index value $\left(T_{i}=0.54, T_{w}=\right.$ 0.69) in the nominal scenario the akin ITAE values of the other scenarios were compared.

Our results suggest that when the system is resilient to systems dynamics, it is not robust to uncertainties in lead-time, especially when lead-time increases. With increases of $25 \%$ and $50 \%$ of the lead-time, the resilience performance would worsen $69 \%$ and $176 \%$, respectively.

In order to determine whether the percentage of changes in the resilience performance is considered high or low, we compared these results with non-optimum resilient regions. We 
Table 3: Robustness test for inventory responses in linear case

\begin{tabular}{ccccc}
\hline $\boldsymbol{T}_{\boldsymbol{p}}$ & ITAE & $\boldsymbol{T}_{\boldsymbol{p}} \boldsymbol{T}_{\boldsymbol{w}}$ & $\boldsymbol{T}_{\boldsymbol{p}} / \boldsymbol{T}_{\boldsymbol{i}}$ & \% Change in Performance \\
\hline 4 & 0.32 & 5.83 & 7.39 & $-68 \%$ \\
6 & 0.59 & 8.75 & 11.08 & $-41 \%$ \\
8 & 1 & 11.67 & 14.78 & $\mathrm{NA}$ \\
10 & 1.69 & 14.58 & 18.47 & $69 \%$ \\
12 & 2.76 & 17.51 & 22.17 & $176 \%$ \\
\hline
\end{tabular}

considered the designs suggested by John et al. (1994); Sterman (1989) and Shukla et al. $(2009)\left(T_{a}=16,4,16 ; T_{i}=8,8,8 ; T_{w}=16,8,6\right.$; respectively). We found that $\pm 25 \%$ and $\pm 50 \%$ changes in lead-time would normally provoke changes of around $\pm 25 \%$ and $\pm 50 \%$ in the ITAE values. Hence we find that a less resilient design, which also yields a lower production on-costs, has the advantage of being more robust.

In Summary, Figure 9 demonstrates different regions of parameter settings which correspond to high resilience (Region A), high robustness (Region B) and low production on-costs (Region C). Region D was chosen as a possible trade-off between the three other regions. Figure 9 also illustrates the order rate and inventory responses to a step change in demand for different lead-times in these regions. In the resilient region A, we have a quick inventory response and recovery for the nominal scenario. However, as lead-time changes, considerable changes in step response characteristics are observed: the error between target and actual values becomes larger and especially the time to recover inventory increases. In other words, since this parameter setting provides a quick response in inventory, an increase in lead-time provokes overshoots and longer duration errors. For the robust region B, changes in leadtime do not greatly affect the time of inventory recovery. Nevertheless, with this setting, the system responds and recovers more slowly and is less ready to serve as the trough values are greater. Another observation is that peaks for order rate in the robust Region $\mathrm{B}$ are lower, implying that robust systems yield lower production on-cost. In the region where the increase of production overheads due to system dynamics is lower (Region $\mathrm{C}$ ), the recovery 
of inventory is even slower. As expected, keeping production orders smooth results in lack of supply chain resilience. Region D yields a response that is less resilient but more robust to changes in lead-time when compared to Regions A and B. From the inventory and order rate responses, it is observed that when lead-time increases, both system responses neither over or undershoot.

It is valid to emphasise that, since the ITAE penalises long duration errors, when leadtime is increased the ITAE value will significantly increase non-linearly. 

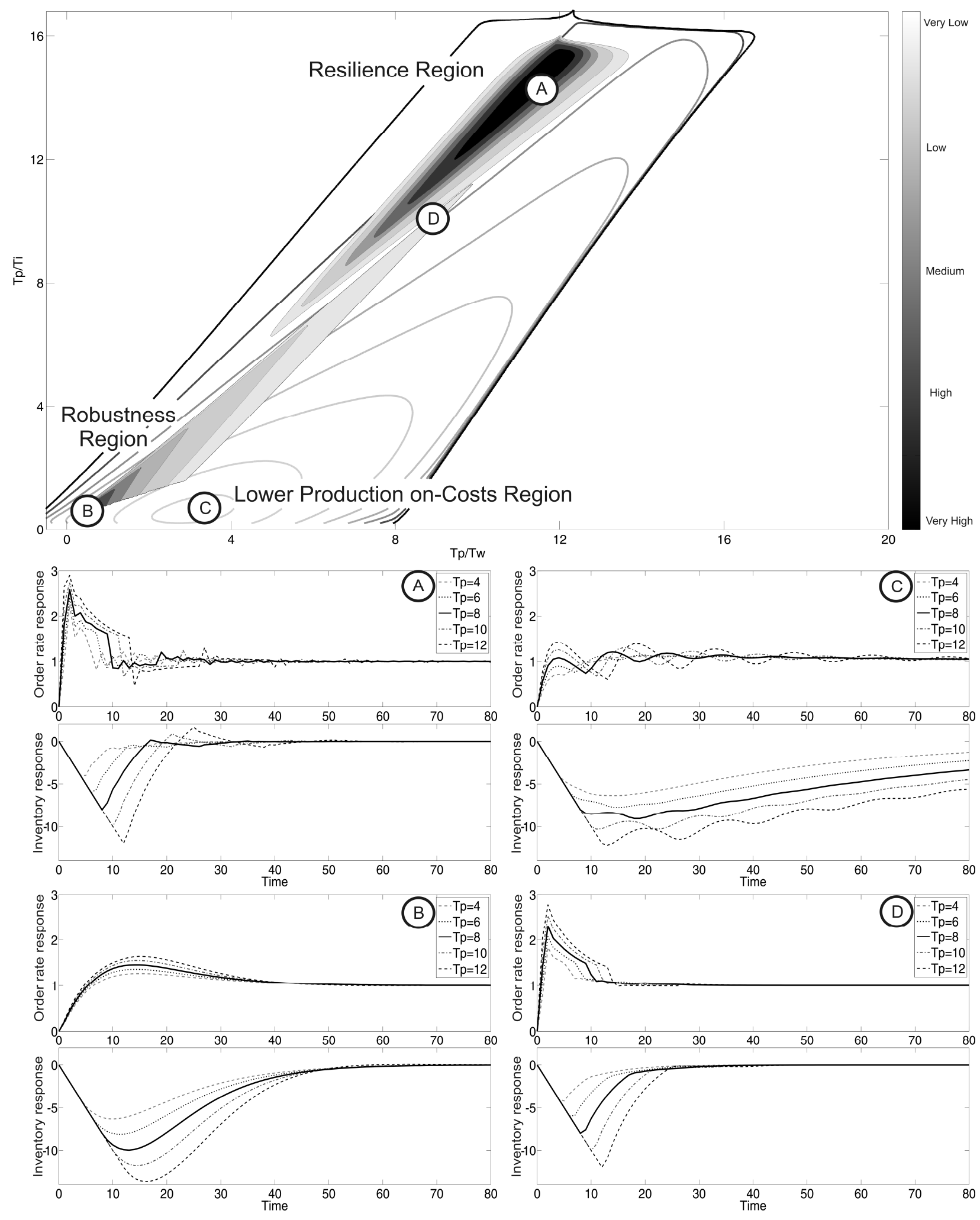

30

Figure 9: Robustness, Resilience and Production on-costs regions 


\subsection{Analysis of the non-linear case: backlog situation}

In the non-linear case we found that it is important not only to examine the variation in inventory but also the outbound shipment profiles for evaluating the resilience performance. When there is sufficient inventory and shipment capacity, the shipments to customers will be the same as the demand. On the other hand, when there is stockout and orders are backlogged, the amount of goods delivered to customers will vary over time.

Our initial model, where we consider only the inventory responses for evaluating supply chain resilience, was insufficient to evaluate resilience problems arising from backlog situations. We also have to minimise the errors between current shipments and demand, which means that we should avoid stockouts. In the linear case, shipments are assumed to be equal to the demand even with negative inventories. Hence ITAE values for shipments in the linear case are always zero.

The target inventory is more important in this case because it determines whether orders will be backlogged and, consequently, whether shipments will be disturbed. We are still considering that the target inventory is equal to zero. Hence, after a step change in demand, all customer orders will be immediately backlogged and we evaluated which set of parameters minimise the ITAE on shipments.

Since we are only considering one echelon with unconstrained supply of raw material, the inventory responses in the non-linear case will be the same as in the linear case, so there is no need to repeat the inventory results. Figure 10 illustrates the quicker response and recovery

regions (Regions $\mathrm{A}$ and $\mathrm{E}$ ) for shipments together with the robustness region (Region $\mathrm{B}$ ), the low production on-costs (Region C) and the trade-off Region D. Since Region E does not appear in the linear result, we provided the plots of both shipments and inventory responses in Figure 10 for this region only. 

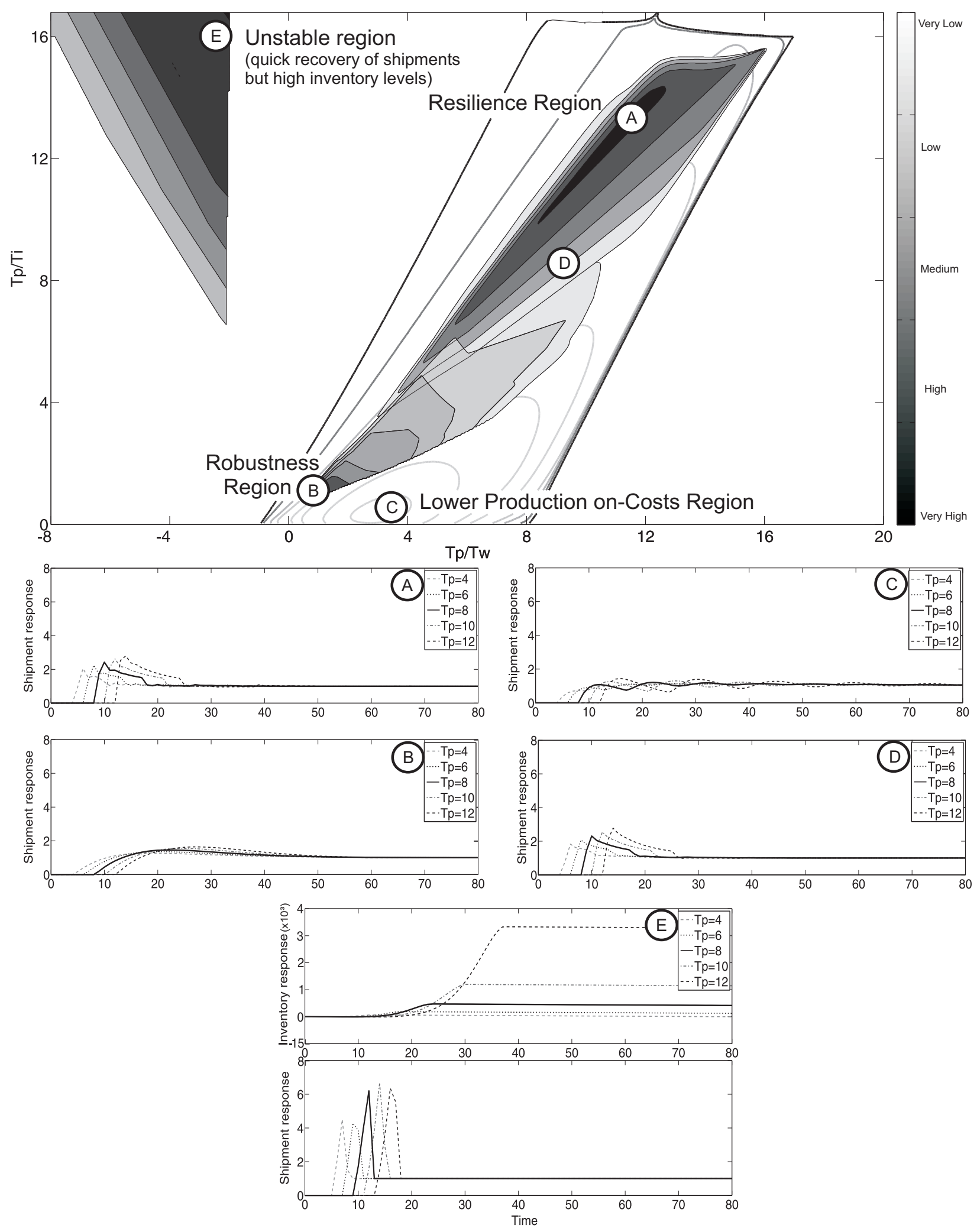

32

Figure 10: Robustness and Resilience regions for shipments in case of backlog 
Note that there are two regions of parameter settings that minimises the ITAE values in shipments, Regions A and E. However, Region E corresponds to the unstable region. From the inventory and shipment responses plots, also in Figure 10, it is possible to visualise that shipments recover very quickly but at the expense of a steady state error in inventory. In order to evaluate the supply chain resilience on the case of backlog situations both shipment and inventory responses must be taken into account. Hence, we are interested in the intersection regions between Figures 9 and 10. Advantageously, minimum ITAE values for shipments within the stable region are located in similar region as for inventory. As a matter of fact, the responses in Region A provide a quick response and recovery of both inventory and deliveries. The responses illustrate that, since the initial inventory is equal to zero, no deliveries are initially made. At this point, the orders placed to suppliers are increased so as to recover the error in inventory. Later, practically all the materials received are dispatched to the customer, causing peaks of shipments. On the other hand, in the robust region B and lower production on-cost region $\mathrm{C}$, the shipments and inventory take longer to recover. However, the smoother response on shipments would imply lower transportation costs. In other words, another trade-off, between transportation costs and resilience, was found.

\section{Sensitivity Analysis}

Again using $T_{p}=8$ as a nominal design, we investigated how changes in lead-time will affect resilience performance in the case of stockout. As with the inventory ITAE the actual minimum shipment ITAE values also increase. The observed size of the area of minimum ITAE for shipments also decrease with larger lead-times (see Figure 11), but it does not seem to be as sensitive as for inventory. However, since we need to consider both inventory and shipment responses for evaluating supply chain resilience in the non-linear model, the resilience area is governed by the minimum inventory ITAE region. This is an important result because the supply chain may potentially sacrifice an increase in inventory levels in order to maintain continued shipments to the customer.

The robustness results for ITAE of shipments again indicate that the system is not robust 
to uncertainties in lead-time when opting for resilient responses. As already shown in Figure 10, the robustness region is different of the resilient one.

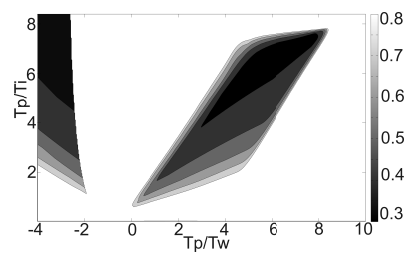

(a) $T_{p}=4$

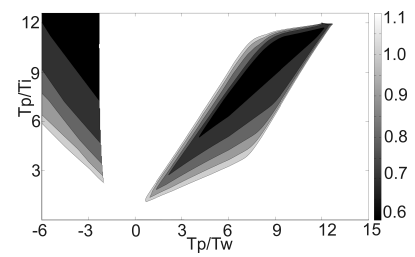

(b) $T_{p}=6$

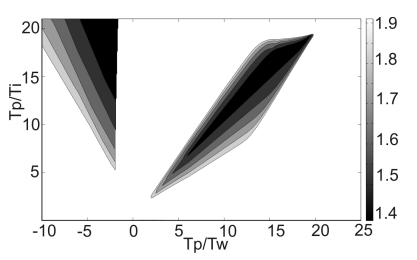

(c) $T_{p}=10$

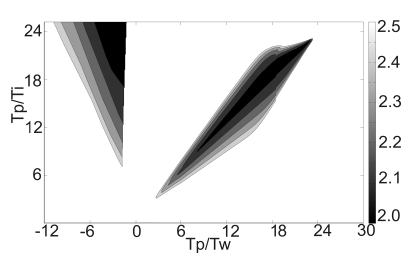

(d) $T_{p}=12$

Figure 11: Assessing robustness on shipment responses due to changes in lead-time

\subsection{Discussion}

In summary, we have identified five different regions for a supply chain design. Table 4 summarises the results obtained for both the linear and non-linear cases as shown in Figures 9 and 10. The table provides numerical values which evidence the difference between the five regions. If the supply chain is designed with parameter settings as in Region A, the system response will be highly resilient but also costly and not robust. This is evidenced by reasonably short time to recover inventory and shipments and shallow troughs in inventory responses, high percentage changes in order rate $(\mathrm{O})$, inventory (I) and shipment(S) performances and high peaks in order rate. The peak in shipments is relatively high as well, but the resilience of the response is guaranteed by short recovery times. This design is recommended for supply chains whose cost of not meeting customer expectations is very high. Also, in order to cope with low robustness the supply chain should make efforts to keep lead-times constant.

Designing the supply chain within Region B will provide robust responses, with medium production on-costs but low resilience. This is evidenced by less sensitive responses in the case of a sudden increase in lead-time. However, the recovery times for shipments and inventory are, respectively, 1.7 and 2.1 times longer than in design Region A and inventory troughs are deeper. This design is recommended for supply chains whose lead-times may 
vary significantly, but these supply chains will be more vulnerable in case of disruption, especially due to external factors.

Region $\mathrm{C}$ is a risky region to be in. Supply chains designed within this set of parameters will not be able to cope with any kind of uncertainty. Demand must be steady, production lead-times must be precise and suppliers must be committed due to very slow response in inventory and shipments, as the time to recover inventory is over 500 weeks. The advantage of this design is the low production on-costs achieved by low peaks in order rate. Another observation is that, in this region, the order rate response is robust to changes in lead-time. This implies that the production on-cost performance would not change significantly in case of lead-time increases. However, there is the eminent risk of low customer satisfaction.

The trade-off region, Region D, is perhaps the best design for supply chains willing to perform fairly resiliently against many sources of risks and, at the same time, moderately keeping this resilience performance in case of lead-time changes. Hence, the system has medium robustness and medium resilience. In relation to production on-costs, the supply chain has to compromise as well. However, according to the sensitivity analysis, production on-cost performance is robust against uncertain lead-time.

Finally, the parameter settings in Region E are highly undesirable. While shipment recovery is very fast, only 12 weeks, the high peak of +6.1 implies that the supply chain would need high shipment capacity. In addition to this, the supply chain would not maintain Minimum Reasonable Inventory since the inventory levels never recover from 470 units. For this reason, ITAE values reach infinity meaning that the system has no resilience and the sensitivity analysis is not applicable. 
Table 4: Summary of Figures 9 and 10

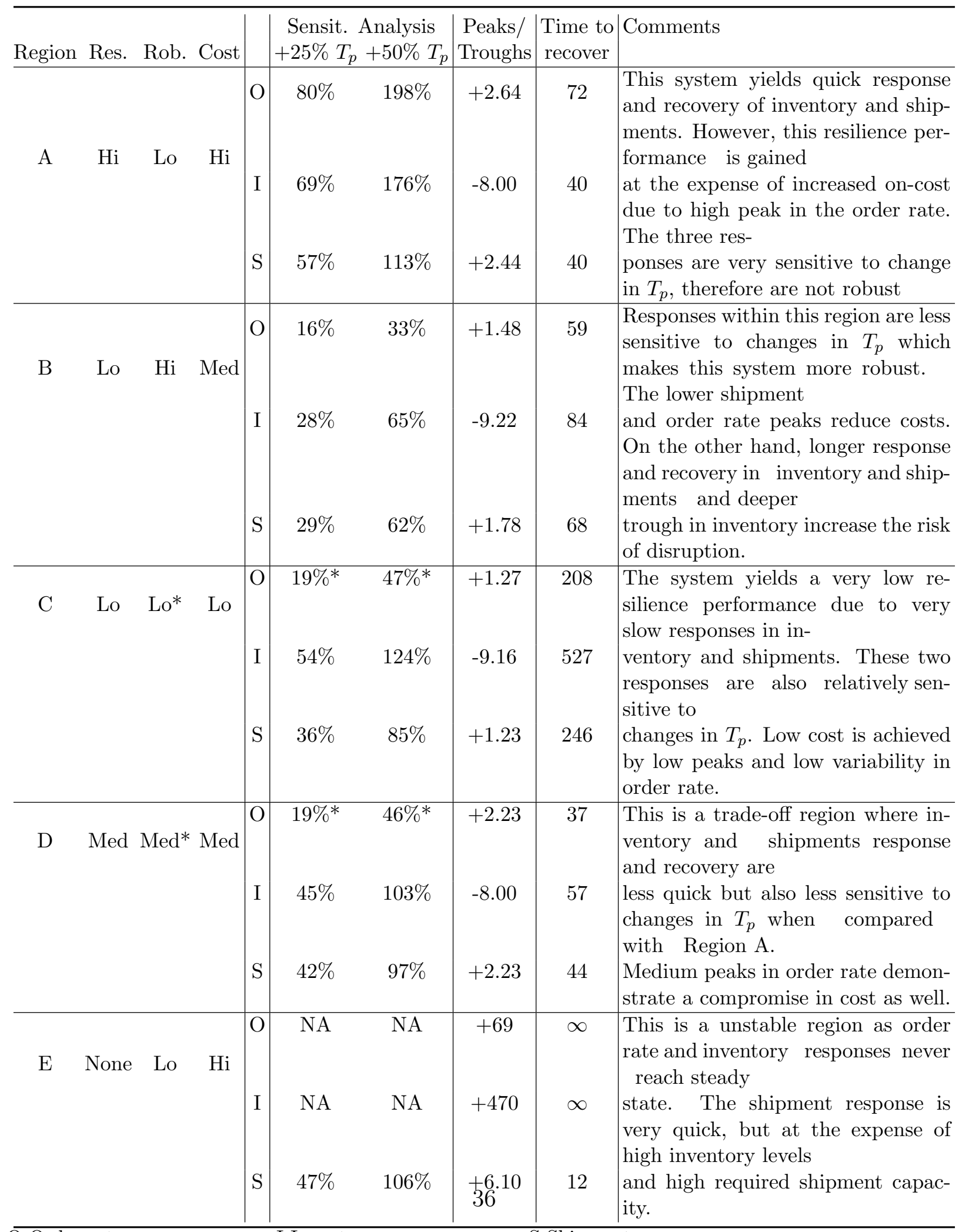

O-Order rate response $\quad$ I-Inventory response $\quad$ S-Shipment response

* Cost performance can be considered robust since the order rates are not sensitive to changes in $T_{p}$ 


\section{Conclusion}

In answer to our first research question, this paper has explored resilience of supply chains from a systems dynamics perspective defined as "the adaptive capability of the supply chain to prepare for unexpected events, respond to disruptions, and recover from them by maintaining continuity of operations at desired levels of connectedness and control over structure and function". The investigation of resilience is further supplemented by due consideration of robustness as well as the impact of resilience on production on-costs. Our definition for supply chain robustness was derived from control engineering and the natural sciences and implies that the system has acceptable changes in performances due to changes in uncertain parameters. The performances in question are resilience and production on-cost and the uncertain parameter we consider is the lead-time.

With regards to the second research question, we have identified the ITAE as a possible measure of resilience when considering inventory and shipment levels. We find that a highly resilient system has the disadvantage of high production on-costs and low robustness. Our

results indicate that, as we have defined robustness from a quantitative control engineering perspective, rather than a qualitative social science perspective, there is a trade-off required between the degree of robustness and resilience. Such a conclusion supplements previous advocated 'conservative' system designs for APIOBPCS which, although producing lower production on-costs and are more robust, are not highly resilient.

Finally, the answer to our third research question involves consideration of the following points:

1. Supply chain dynamics play an important role in resilience due to delays and feedback information in the system. For a given control policy we find that the choice of decision parameter affects the degree of resilience and robustness that the system has.

2. We analytically demonstrate the trade-off between production on-costs and supply chain resilience. We identified two circumstances of the ordering policy which resulted in increased resilience but high on-costs: a) decreasing the times to recover inventory $\left(T_{i}\right)$ and WIP $\left(T_{w}\right)$ in the ordering control algorithm and $b$ ) moving from a levelling 
strategy to a chase strategy. Regarding the former, as managers make efforts to recover inventory quicker and hence achieve resilience, the variation in the order rates will raise leading to increased costs as the supply chain production capacity ramps up and down. On the other hand, by increasing $T_{i}$ and $T_{w}$ and having a higher degree of smoothing, there may be some compromise in resilience but resulting in a considerable decrease in production on-costs. In the latter case, approaching a chase strategy by decreasing the time to smooth demand $\left(T_{a}\right)$, resilience is also improved.

3. Another trade-off identified is between transportation on-costs and resilience. When backlogs occur, a large quantity of goods needs to be shipped in a short period of time in order to recover inventory targets as fast as possible. Hence, transportation costs increase with the need for increased spare capacities or the hiring of third party logistics providers with associated premium freight rates. However, we also show that in the trade-off region, these shipment peaks can be reduced.

4. Using engineering definitions and tools for measuring resilience and robustness and applying them to supply chain management, we found that these two desired criteria are not always achieved simultaneously. In fact, in our model, we found that a resilient design yields responses that are very sensitive to changes in lead-time. The lower the lead-time, the more resilient the supply chain is. However, any unexpected increases in lead-time will result in considerable deviation from nominal performance.

5. By investigating different control policies, we explore supply chain design as a mitigation strategy. The literature suggests many designs which yield decreased production costs and robust system responses. However, no previous system dynamics research on inventory and ordering control systems have also considered supply chain resilience.

This work is an initial study of the dynamics of supply chain resilience and brings awareness of the complex task of supply chain design in satisfying potentially conflicting desired performances. In particular, supply chains with high uncertainty in lead-times, such as may be found in the electronics sector (Berry et al., 1998), need to trade-off robustness and costeffectiveness against resilience. Companies with certain but long lead-times, such as some 
in the construction sector (Berry et al., 1998), may have some difficulties in being resilient because of long lead-times but can design their system to respond quickly to changes in demand at the expense of increased operational costs. Those companies in an enviable position of having short and consistent lead-times, for instance the grocery industry (Fernie et al., 2000), can more easily design a resilient system with only some compromise in increased costs.

To sum up, our study highlights several practical implications a supply chain designer has to consider before developing an inventory and production control system that is more resilient.

This paper is limited to the dynamics of a single echelon with a specific inventory and ordering control policy. Further research, motivated by the analytical research and due consideration of the literature review, includes;

1. Considering different inventory policies in order to compare inventory costs and supply chain resilience. In this way, it will be possible to recommend appropriate inventory policies for different supply chain requirements.

2. Exploring resilience from a dyadic to a multi-echelon supply chain perspective in order to determine alternative collaborative strategies, including altruistic behaviour, in sharing capacity across the supply chain.

3. Extending the developed resilience performance measure to MTO supply chain models and verify how lead-time errors, response and recovery can be minimised.

4. Taking the latter two points together, extend the model to multiple echelons and investigate resilience of MTS-MTO decoupled supply chains.

\section{References}

Asbjørnslett, B. E., 2008. Assessing the vulnerability of supply chains. In: Zsidisin, G. A., Ritchie, B. (Eds.), Supply Chain Risk: A Handbook of Assessment, Management and Performance. Springer, New York, NY. 
Ashton, D., 1998. Systematic risk and empirical research. Journal of Business Finance and Accounting 25 (9/10), 1325-1356.

Berry, D., Evans, G. N., Naim, M. M., February 1998. Pipeline information survey: a uk perspective. Omega 26 (1), 115-131.

Bettis, R. A., Thomas, H., 1990. Risk, strategy, and management. JAI Press.

Boin, A., Kelle, P., Clay Whybark, D., July 2010. Resilient supply chains for extreme situations: Outlining a new field of study. International Journal of Production Economics $126(1), 1-6$.

Carvalho, H., 2011. Resilience index: Proposal and application in the automotive supply chain. Proceedings of the 18th EUROMA Conference, Cambridge, UK, 3-6 July.

Christopher, M., Peck, H., 2004. Building the resilient supply chain. International Journal of Logistics Management 15 (2), 1-14.

Christopher, M., Rutherford, C., 2004. Creating supply chain resilience through agile six sigma. CriticalEYE Publications June-August, http://martin-christopher.info/ wp-content/uploads/2009/12/critical_eye.pdf [Accessed 1 AUG 2010].

Colicchia, C., Creazza, A., Dallari, F., 2010a. Supply chain risk management: insights from an explorative study in the italian industry. Logistics Research Network Annual Conference proceedings, Leeds, UK, 8-10 September.

Colicchia, C., Dallari, F., Melacini, M., 2010b. Increasing supply chain resilience in a global sourcing context. Production Planning \& Control: The Management of Operations 21 (7), $680-694$.

Datta, P. P., Christopher, M., Allen, P., 2007. Agent-based modelling of complex production/distribution systems to improve resilience. International Journal of Logistics: Research and Applications 10 (3), 187-203. 
Disney, S. M., Grubbström, R. W., 2004. Economic consequences of a production and inventory control policy. International Journal of Production Research 42 (17), 3419-3431.

Disney, S. M., Towill, D. R., 2002. A discrete transfer function model to determine the dynamic stability of a vendor managed inventory supply chain. International Journal of Production Research 40 (1), 179-204.

Disney, S. M., Towill, D. R., Warburton, R. D. H., 2006. On the equivalence of control theoretic, differential, and difference equation approaches to modeling supply chains. International Journal of Production Economics 101 (1), 194-208.

Dorf, R. C., Bishop, R. H., 1998. Modern Control Systems. Addison Wesley Longmann, Inc.

Falasca, M., Zobel, C. W., Cook, D., 2008. A decision support framework to assess supply chain resilience. Proceedings of the 5th International ISCRAM Conference, Washington, USA, May.

Fernie, J., Pfab, F., Marchant, C., 2000. Retail grocery logistics in the uk. The International Journal of Logistics Management 11 (2), 83-90.

Forrester, J. W., 1961. Industrial Dynamic. MIT Press, Boston, MA.

Grünwald, H. J., Fortuin, L., 1992. Many steps towards zero inventory. European Journal of Operational Research 59 (3), 359-369.

John, S., Naim, M. M., Towill, D., 1994. Dynamic analysis of a wip compensated decision support system. International Journal of Manufacturing System Design 1 (4), 283-297.

Jüttner, U., Peck, H., Christopher, M., 2003. Supply chain risk management: outlining an agenda for future research. International Journal of Logistics: Research and Applications Vol. 6, No. 4, 20036 (4), 197-210.

Kahnemann, D., Tversky, A., 1979. Prospect theory: an analysis of decision under risk. Econometrica 47 (2), 263-292. 
Lassar, W. M., Kerr, J. L., 1996. Strategy and control in supplier-distributor relationships: an agency perspective. Strategic Management Journal 17 (8), 613-632.

Lodree Jr., E. J., Taskin, S., 2007. An insurance risk management framework for disaster relief and supply chain disruption inventory planning. Journal of the Operational Research Society 59 (5), 1-11.

March, J. G., Shapira, Z., 1987. Managerial perspectives on risk and risk taking. Management Science 33 (11), 1404-1418.

Marques, V. L., Naim, M. M., Disney, S. M., 2010. The impact of capacitated logistics operations on supply chain dynamics. Proceedings of the 16th International Working Seminar on Production Economics, Innsbruck, 1-5 March, Austria, Pre-Prints, Vol. 3., pp. 365-376.

Mason-Jones, R., Towill, D., 1998. Shrinking the supply chain uncertainty circle. Control $24(7), 17-23$.

McManus, S., Seville, E., Brunsdon, D., Vargo, J., 2007. Resilience management: A framework for assessing and improving the resilience of organisations. Christchurch, New Zealand: Resilient Organisations (www.resorgs.org.nz).

Mitra, K., Gudi, R. D., Patwardhan, S. C., Sardar, G., 2009. Towards resilient supply chains: Uncertainty analysis using fuzzy mathematical programming. Computer Aided Chemical Engineering 87 (7), 967-981.

Newman, W. R., Hanna, M., Maffei, M. J., 1993. Dealing with the uncertainties of manufacturing: flexibility, buffers and integration. International Journal of Operations and Production Management 13 (1), 19-34.

Oliver, R. K., Webber, M. D., 1982. Supply chain management: Logistics catches up with strategy. In: Christopher, M. (Ed.), Logistics: The Strategic Issues. Chapman \& Hall, pp. $63-75$. 
Pagell, M., Krause, D. R., 1999. A multiple-method study of environmental uncertainty and manufacturing flexibility. Journal of Operations Management 17 (3), 307-326.

Peck, H., 2005. Drivers of supply chain vulnerability: an integrated framework. International Journal of Physical Distribution and Logistics Management 35 (4), 210-232.

Pettit, T. J., Fiksel, J., Croxton, K. L., 2010. Ensuring supply chain resilience: development of a conceptual framework. Journal of Business Logistics 31 (1), 1-21.

Ponomarov, S. Y., Holcomb, M. C., 2009. Understanding the concept of supply chain resilience. International Journal of Logistics Management 20 (1), 124-143.

Pytel, A., Kiusalaas, J., 2003. Mechanics of Materials. Cengage Learning, Stamford, USA.

Ratick, S., Mecham, B., Aoyama, Y., 2008. Locating backup facilities to enhance supply chain disaster resilience. Growth and Change 39 (4), 642-666.

Sheffi, Y., 2005. Building a resilient supply chain. Harvard Business Review 1 (8), 1-5.

Sheffi, Y., Rice, J. B., 2005. A supply chain view of the resilient enterprise. MIT Sloan Management Review 47 (1), 41-48.

Shukla, V., Naim, M. M., Yaseen, E. A., 2009. 'Bullwhip' and 'backlash' in supply pipelines. International Journal of Production Research 47 (23), 6477-6497.

Skipper, J. B., Hanna, J. B., 2009. Minimizing supply chain disruption risk through enhanced flexibility. International Journal of Physical Distribution and Logistics Management 39 (5), $404-427$.

Stalk, G., Hout, T., 1990. Competing against Time. The Free Press, New York, NY.

Sterman, J. D., 1989. Modelling managerial behaviour: misperceptions of feedback in a dynamic decision making experiment. Management Science 35 (3), 321-339.

Tang, C., Tomlin, B., 2008. The power of flexibility for mitigating supply chain risks. International Journal of Production Economics 116 (1), 12-27. 
Tierney, K., Bruneau, M., 2007. Conceptualizing and measuring resilience: a key to disaster loss reduction. TR news May-June (250), 14-17.

Tomlin, B., 2006. On the value of mitigation and contingency strategies for managing supply chain disruption risks. Management Science 52 (5), 639-657.

Towill, D. R., Naim, M. M., Wikner, J., 1992. Industrial dynamics simulation models in the design of supply chains. International Journal of Physical Distribution \& Logistics Management 22 (5), 3-13.

Wagner, S. M., Neshat, N., 2010. Assessing the vulnerability of supply chains using graph theory. International Journal of Production Economics 126 (1), 121-129.

Wikner, J., Naim, M. M., Rudberg, M., 2007. Exploiting the order book for mass customized manufacturing control systems with capacity limitations. IEEE Transactions on Engineering Management 54 (1), 145-155.

Wikner, J., Naim, M. M., Towill, D. R., 1992. The system simplification approach in understanding the dynamic behaviour of a manufacturing supply chain. Journal of Systems Engineering 2, 164-178.

Wilson, M., 2007. The impact of transportation disruptions on supply chain performance. Transportation Research Part E: Logistics and Transportation Review 43 (295-320), 4.

Yates, J. F., Stone, E. R., 1992. The risk construct. In: Yates, J. (Ed.), Risk Taking Behavior. Wiley, New York, pp. 1-25.

Zsidisin, G. A., 2003. A grounded definition of supply risk. Journal of Purchasing and Supply Managemen 9 (5-6), 217-224. 


\section{A. Linear inventory responses to a unit step input}

Table 5: Inventory equations and ITAE values for overdamped responses cases

\section{CASE 1: Distinct poles: real and/or complex}

$$
\begin{aligned}
& \operatorname{ainv}(t)=A \cdot e^{-\frac{t}{T_{a}}}+B \cdot e^{\sigma_{p_{1}} t}\left[\cos \left(\omega_{p_{1}} t\right)-j \cdot \sin \left(\omega_{p_{1}} t\right)\right]+C \cdot e^{\sigma_{p_{2}} t}\left[\cos \left(\omega_{p_{2}} t\right)-j . \sin \left(\omega_{p_{2}} t\right)\right] \\
& A=\frac{-T_{i} T_{a}^{3}\left(T_{w}+T_{p}\right)}{\left(T_{a} p_{1}+1\right)\left(T_{a} p_{2}+1\right)} \cdot \frac{1}{T_{a} T_{i} T_{w} T_{p}} \\
& B=\frac{-T_{i}\left(T_{a} T_{w}+T_{a} T_{p}+T_{w} T_{p}+p_{1} T_{a} T_{w} T_{p}\right)}{\left(p_{1}-p_{2}\right)\left(p_{1}+1 / T_{a}\right)} \cdot \frac{1}{T_{a} T_{i} T_{w} T_{p}} \\
& C=\frac{-T_{i}\left(T_{a} T_{w}+T_{a} T_{p}+T_{w} T_{p}+p_{2} T_{a} T_{w} T_{p}\right)}{\left(p_{2}-p_{1}\right)\left(p_{2}+1 / T_{a}\right)} \cdot \frac{1}{T_{a} T_{i} T_{w} T_{p}} \\
& D=\frac{T_{a}}{p_{1} p_{2}}\left(T_{i} \bar{T}_{p}-T_{i} T_{p}\right) \cdot \frac{1}{T_{a} T_{i} T_{w} T_{p}}=0
\end{aligned}
$$

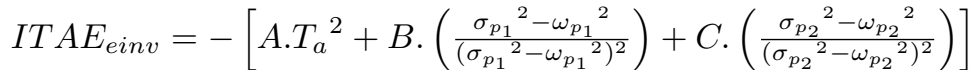

CASE 2: Repeated poles: when $p_{1}=p_{2}=p$ but $p \neq-\frac{1}{T_{a}}$

$\operatorname{ainv}(t)=A \cdot e^{-\frac{t}{T_{a}}}+B \cdot e^{p t}+C \cdot t \cdot e^{p t}$

$$
\begin{aligned}
A & =\frac{-T_{i} T_{a}{ }^{3}\left(T_{w}+T_{p}\right)}{\left(T_{a} p+1\right)^{2}} \cdot \frac{1}{T_{a} T_{i} T_{w} T_{p}} \\
B & =\frac{T_{i} T_{a}{ }^{3}\left(T_{w}+T_{p}\right)}{\left(T_{a} p+1\right)^{2}} \cdot \frac{1}{T_{a} T_{i} T_{w} T_{p}} \\
C & =\frac{-T_{i}\left(T_{a} T_{w}+T_{a} T_{p}+T_{w} T_{p}+p T_{a} T_{w} T_{p}\right)}{\left(p+1 / T_{a}\right)} \cdot \frac{1}{T_{a} T_{i} T_{w} T_{p}} \\
D & =0
\end{aligned}
$$

$I T A E_{e i n v}=-\left[A \cdot T_{a}{ }^{2}+\frac{B}{p^{2}}+\frac{2 C}{p^{3}}\right]$

CASE 3: Repeated poles: when $p_{1}=p_{2}=-1 / T_{a}=p$

$$
\operatorname{ainv}(t)=B \cdot t \cdot e^{p t}+\frac{1}{2} C \cdot t^{2} \cdot e^{p t}
$$

$A=0$

$B=-1$

$C=-T_{i}\left(T_{w} T_{p}+T_{a} T_{p}+T_{a} T_{w}+p T_{a} T_{w} T_{p}\right) \cdot \frac{1}{T_{a} T_{i} T_{w} T_{p}}$

$D=0$

$$
I T A E_{\text {einv }}=-\left[\frac{2 B}{p^{3}}+\frac{3 C}{p^{4}}\right]
$$

CASE 4: Repeated poles: when $p_{1}=-1 / T_{a}$ or $p_{2}=-1 / T_{a}$
a) $p_{1}=-1 / T_{a}=p$
b) $p_{2}=-1 / T_{a}=p$
$\operatorname{ainv}(t)=A \cdot e^{p t}+B \cdot t \cdot e^{p t}+C \cdot e^{p_{2} t}$
$\operatorname{ainv}(t)=A \cdot e^{p t}+B \cdot e^{p_{1} t}+C \cdot t \cdot e^{p t}$
$A=\frac{T_{i}\left(T_{w} T_{p}+T_{a} T_{p}+T_{a} T_{w}+p_{2} T_{a} T_{w} T_{p}\right)}{\left(p_{2}-p\right)^{2}} \cdot \frac{1}{T_{a} T_{i} T_{w} T_{p}}$
$B=\frac{-T_{i}\left(T_{a} T_{w}+T_{a} T_{p}+T_{w} T_{p}+p T_{a} T_{w} T_{p}\right)}{p-p_{2}} \cdot \frac{1}{T_{a} T_{i} T_{w} T_{p}}$
$C=\frac{-T_{i}\left(T_{w} T_{p}+T_{a} T_{p}+T_{a} T_{w}+p_{2} T_{a} T_{w} T_{p}\right)}{\left(p_{2}-p\right)^{2}} \cdot \frac{T_{a} T_{i} T_{w} T_{p}}{T_{a} T_{i} T_{w} T_{p}}$
$D=0$
$A=\frac{T_{i}\left(T_{w} T_{p}+T_{a} T_{p}+T_{a} T_{w}+p_{1} T_{a} T_{w} T_{p}\right)}{\left(p_{1}-p\right)^{2}} \cdot \frac{1}{T_{a} T_{i} T_{w} T_{p}}$
$B=\frac{-T_{i}\left(T_{w} T_{p}+T_{a} T_{p}+T_{a} T_{w}+p_{1} T_{a} T_{w} T_{p}\right)}{\left(p_{1}-p\right)^{2}} \cdot \frac{1}{T_{a} T_{i} T_{w} T_{p}}$
$C=\frac{-T_{i}\left(T_{a} T_{w}+T_{a} T_{p}+T_{w} T_{p}+p T_{a} T_{w} T_{p}\right)}{p-p_{1}} \cdot \frac{1}{T_{a} T_{i} T_{w} T_{p}}$
$D=0$
$I T A E_{\text {einv }}=-\left[\frac{A}{p^{2}}+\frac{2 B}{p^{3}}+\frac{C}{p_{2}^{2}}\right]$
$I T A_{4} E_{\text {einv }}=-\left[\frac{A}{p^{2}}+\frac{B}{p_{1}^{2}}+\frac{2 C}{p^{3}}\right]$ 


\section{B. Non-linear difference equations}

Table 6: Difference equations e and initial settings (IS) for non-linear case

\begin{tabular}{|c|c|c|}
\hline Description & Difference equation & IS \\
\hline Time period & $\mathrm{t}$, in weeks & \\
\hline Consumption & $\operatorname{CONS}(t)=\left\{\begin{array}{l}0, \text { if } t \leq 0 \\
1, \text { if } t>0\end{array}\right.$ & 0 \\
\hline Shipment received & $\operatorname{INSHIP}(t)=O R A T E(t-T p)$ & 0 \\
\hline Maximum shipping & $M A X S H I P(t)=A I N V(t-1)+\operatorname{INSHIP}(t)$ & NA \\
\hline Desired shipping & $D S H I P(t)=B A C K L O G(t-1)+C O N S J(t)$ & NA \\
\hline Shipment & $S H I P(t)=M I N[D S H I P(t), M A X S H I P(t)]$ & 0 \\
\hline Actual inventory & $A I N V(t)=A I N V(t-1)+\operatorname{INSHIP}(t)-\operatorname{SHIP}(t)$ & 0 \\
\hline Backlog & $B A C K L O G(t)=B A C K L O G(t-1)+C O N S(t)-S H I P(t)$ & 0 \\
\hline Average CONS & $A V C O N(t)=A V C O N(t-1)+\frac{1}{1+T a}(C O N S J(t)-A V C O N(t-1))$ & 0 \\
\hline Desired WIP & $D W I P(t)=T p \times A V C O N(t)$ & NA \\
\hline Work in process & $W I P(t)=\sum_{i=1}^{T} O R A T E(t-T p-i)$ & 0 \\
\hline Error in WIP & $E W I P(t)=D W I P(t)-W I P(t)$ & NA \\
\hline Desired inventory & $D I N V(t)=12$ & 0 \\
\hline Error in inventory & $E I N V(t)=D I N V(t)-A I N V(t)+B A C K L O G(t)$ & NA \\
\hline Order rate & $O R A T E(t)=M A X\left[0, A V C O N(t-1)+\frac{E I N V(t-1)}{T i}+\frac{E W I P(t-1)}{T w}\right]$ & NA \\
\hline
\end{tabular}

Adapted from: Shukla et al., 2009 